\title{
Hypoxic pulmonary vasoconstriction requires connexin 40-mediated endothelial signal conduction
}

\author{
Liming Wang, 1,2,3,4 Jun Yin,, 1,2,3,4 Hannah T. Nickles, ${ }^{2}$ Hannes Ranke,,1,2 Arata Tabuchi, ${ }^{1}$ \\ Julia Hoffmann, ${ }^{2}$ Christoph Tabeling, ${ }^{5}$ Eduardo Barbosa-Sicard, ${ }^{6}$ Marc Chanson, ${ }^{7}$ \\ Brenda R. Kwak, ${ }^{8}$ Hee-Sup Shin, ${ }^{9}$ Songwei Wu, ${ }^{10}$ Brant E. Isakson, ${ }^{11}$ Martin Witzenrath, ${ }^{5}$ \\ Cor de Wit, ${ }^{12}$ Ingrid Fleming, ${ }^{6}$ Hermann Kuppe, ${ }^{4}$ and Wolfgang M. Kuebler ${ }^{1,2,4,13}$
}

\begin{abstract}
${ }^{1}$ The Keenan Research Centre at the Li Ka Shing Knowledge Institute, St. Michael's Hospital, Toronto, Ontario, Canada. 2Institute of Physiology, Department of Internal Medicine, Charité-Universitätsmedizin, Berlin, Germany. ${ }^{3}$ Department of Cardiothoracic Surgery, Affiliated People's Hospital of Jiangsu University, Zhenjiang, China. ${ }^{4}$ German Heart Institute, Berlin, Germany.

${ }^{5}$ Division of Infectious Diseases and Pulmonary Medicine, Department of Internal Medicine, Charité-Universitätsmedizin Berlin, Germany. ${ }^{6}$ Institute for Vascular Signalling, Centre for Molecular Medicine, Goethe University Frankfurt, Frankfurt, Germany. ${ }^{7}$ Laboratory of Clinical Investigation III, Hôpitaux Universitaires de Genève (HUG), and ${ }^{8}$ Department of Pathology and Immunology, Université de Genève, Genève, Switzerland. ${ }^{9} \mathrm{Center}$ for Neural Science, Korea Institute of Science and Technology, Seoul, Republic of Korea. ${ }^{10} \mathrm{Center}$ for Lung Biology, University of South Alabama, Mobile, Alabama, USA. ${ }^{11}$ Robert M. Berne Cardiovascular Research Center, Department of Molecular Physiology and Biological Physics, University of Virginia, Charlottesville, Virginia, USA. ${ }^{12}$ Institute of Physiology, University of Lübeck, Lübeck, Germany.

${ }^{13}$ Department of Surgery and Department of Physiology, University of Toronto, Toronto, Ontario, Canada.
\end{abstract}

\begin{abstract}
Hypoxic pulmonary vasoconstriction (HPV) is a physiological mechanism by which pulmonary arteries constrict in hypoxic lung areas in order to redirect blood flow to areas with greater oxygen supply. Both oxygen sensing and the contractile response are thought to be intrinsic to pulmonary arterial smooth muscle cells. Here we speculated that the ideal site for oxygen sensing might instead be at the alveolocapillary level, with subsequent retrograde propagation to upstream arterioles via connexin $40(\mathrm{Cx} 40)$ endothelial gap junctions. HPV was largely attenuated by $\mathrm{Cx} 40$-specific and nonspecific gap junction uncouplers in the lungs of wildtype mice and in lungs from mice lacking $\mathrm{Cx} 40\left(\mathrm{C} x 40^{-/-}\right)$. In vivo, hypoxemia was more severe in $\mathrm{Cx}^{-0^{-/}}$mice than in wild-type mice. Real-time fluorescence imaging revealed that hypoxia caused endothelial membrane depolarization in alveolar capillaries that propagated to upstream arterioles in wild-type, but not $\mathrm{Cx}_{40^{-/}}$, mice. Transformation of endothelial depolarization into vasoconstriction involved endothelial voltage-dependent $\alpha_{1 \mathrm{G}}$ subtype $\mathrm{Ca}^{2+}$ channels, cytosolic phospholipase $\mathrm{A}_{2}$, and epoxyeicosatrienoic acids. Based on these data, we propose that HPV originates at the alveolocapillary level, from which the hypoxic signal is propagated as endothelial membrane depolarization to upstream arterioles in a $\mathrm{Cx} 40$-dependent manner.
\end{abstract}

\section{Introduction}

Hypoxic pulmonary vasoconstriction (HPV) is a fundamental physiological mechanism by which the lung optimizes ventilation/ perfusion $(\mathrm{V} / \mathrm{Q})$ matching, redirecting blood flow from poorly to better ventilated areas (1). Yet in cases of global hypoxia, HPV may unfavorably increase total pulmonary vascular resistance and right ventricular afterload, thus contributing to the clinical pathology of pulmonary hypertension and cor pulmonale in chronic hypoxic lung diseases or to pulmonary edema at high altitude $(1,2)$. While the relevance of HPV has been recognized for over 60 years, the underlying oxygen sensing and signal transduction processes remain a topic of intense research and controversy. Current concepts of HPV are largely based on the notion that pulmonary arterial smooth muscle cells (PASMCs) constitute both the sensor and the transducer of the hypoxic signal as well as its contractile effector (1), while the role of the vascular endothelium is at best considered that of a modulating bystander.

From a conceptual standpoint, the ideal site for an oxygen sensor in HPV is within the actual area of pulmonary gas exchange,

Authorship note: Liming Wang and Jun Yin contributed equally to this work. Conflict of interest: The authors have declared that no conflict of interest exists. Citation for this article: J Clin Invest. 2012;122(11):4218-4230. doi:10.1172/JCI59176. i.e., in the alveolar capillaries or vessels downstream thereof. This would warrant that HPV responds to local alveolar hypoxia rather than to pulmonary arterial hypoxemia, as has been demonstrated experimentally by a series of seminal studies (3). However, the presence of vascular smooth muscle cells $(4,5)$ and a detectable HPV response (6) is confined to pulmonary arterioles and arteries at least $30 \mu \mathrm{m}$ in diameter, which are rather remote from the alveolocapillary area of gas exchange. These considerations suggest a spatial dissociation between oxygen sensor and effector in HPV, which would necessitate the existence of a retrograde signaling mechanism from the alveolar gas exchange unit to medium and large PASMC-bearing arterioles and arteries. In the systemic circulation, such a communication system has been identified and intensely studied in the form of the conducted response, a local membrane hyper- or depolarization that propagates upstream along the vessel wall to feeding resistance arteries via intercellular gap junction channels formed by connexins $(7,8)$.

Among the major connexins expressed in the vascular bed, connexin 40 (Cx40) is of particular interest as it is exclusively expressed in endothelial cells $(9,10)$, the only vascular cell type present at the alveolar gas exchange unit. $\mathrm{Cx} 40$ has been shown to be crucial in the conduction of endothelium-dependent vasodilations in the systemic vasculature $(8,11,12)$ and is abundantly expressed in the 

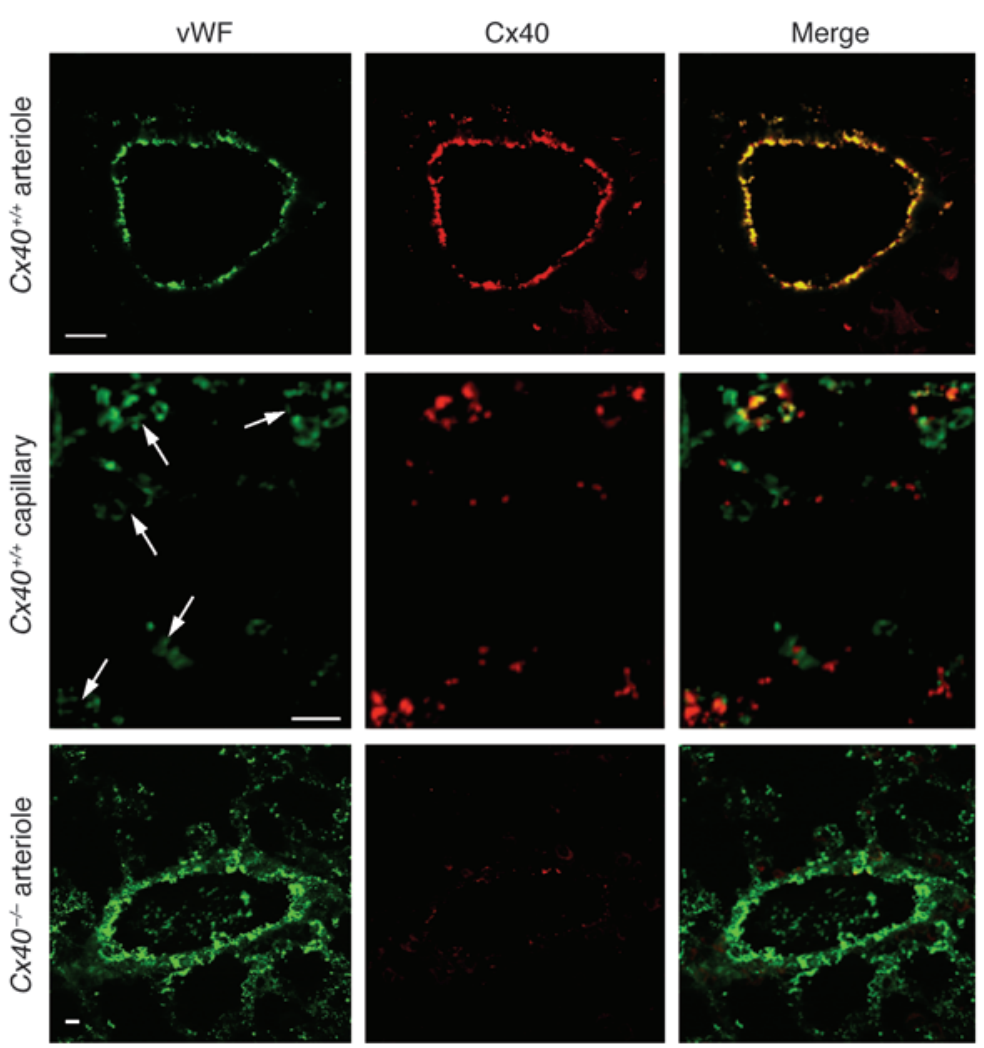
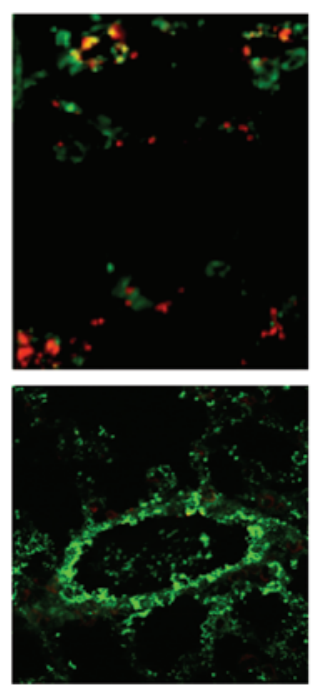

Figure 1

Expression of $\mathrm{Cx} 40$ in pulmonary microvessels. Expression of vWF (green) and Cx40 (red) and merged images for pulmonary arterioles and capillaries (arrows) of $\mathrm{C} \times 40^{+/+}$mice and for arterioles of $C \times 40^{-1-}$ mice. Scale bars: $10 \mu \mathrm{m}$. Note colocalization of vWF and $\mathrm{Cx} 40$ in pulmonary arterioles and capillaries of $\mathrm{Cx} 40^{+/+}$mice, indicative of endothelial Cx40 expression, was absent in $\mathrm{C} \times 40^{-/-}$mice.

and $\Delta \mathrm{R}_{0}$ were largely absent in $C x 40^{-/-}$lungs. Similar attenuation of HPV was detected in $C x 40^{+/+}$lungs perfused with the nonspecific gap junction inhibitor $18 \alpha$-glycyrrhetinic acid $(50 \mu \mathrm{M})$ or the $\mathrm{Cx} 40$-specific inhibitory mimetic peptide gap $27^{40}(200 \mu \mathrm{M}$; Figure $2 \mathrm{C})$. Neither Cx40 deficiency nor pharmacological inhibition of gap junctions by $18 \alpha$-glycyrrhetinic acid or gap $27^{40}$ blocked HPV in response to $1 \mu \mathrm{g}$ Ang II (Figure 2D), which demonstrated that $\mathrm{Cx} 40$ is not required for pulmonary vasoconstriction per se.

We considered the possibility that connexins other than $\mathrm{Cx} 40$ may be downregulated or inactivated in endothelial cells of ${\mathrm{C} x 40^{-/-}}^{-}$mice. $\mathrm{Cx} 43$ is of particular relevance in this context, as it has previously been shown to propagate proinflammatory signals along the lung microvascular endothelium (16), since its role in intercellular communication is critically regulated by its phosphorylation state (17), and since coordinated regulation of both $\mathrm{Cx} 40$ and $\mathrm{Cx} 43$ has been demonstrated in mouse aortic endothelium (18). Similar to $\mathrm{Cx} 40$,

lung (13). In the present study, we tested the hypothesis that $\mathrm{Cx} 40$ is required for the propagation of a conducted response in the pulmonary microvasculature that mediates HPV in the intact lung.

\section{Results}

Cx40 expression in mouse lungs is confined to the vascular endothelium. By double fluorescence immunohistology using vWF as an endothelial-specific antigen, we first determined the distribution of $\mathrm{Cx} 40$ in lungs of wild-type $\left(\mathrm{C} x 40^{+/+}\right)$mice. $\mathrm{Cx} 40$ immunostaining was evident in pulmonary arteries, where it colocalized with vWF (Figure 1). Cx40 was also present in lung capillaries - albeit in a more punctate pattern, in line with its expression at cell-cell contacts (14) - and only partially colocalized with vWF, which in itself showed a characteristic irregular expression in capillaries (15). No $\mathrm{Cx} 40$ staining was detectable in lungs of $\mathrm{Cx} 40$-deficient $\left(\mathrm{C} \times 40^{-/-}\right)$ mice or in extravascular lung parenchyma of $\mathrm{C} x 40^{+/+}$mice.

$\mathrm{C} 440$ is critical for HPV in intact lungs. Next, we addressed the functional relevance of $\mathrm{Cx} 40$ in HPV in isolated perfused lungs of $\mathrm{C} \times 40^{+/+}$and $\mathrm{C} \times 40^{-/-}$mice. Single pressure tracings obtained at normoxia showed characteristic changes in pulmonary arterial pressure (PAP) during variations in perfusate flow in both $\mathrm{C} x 40^{+++}$and $\mathrm{C} \times 40^{-/}$lungs (Figure 2A). After switching to hypoxic ventilation, PAP increased and reached its maximum within approximately 10 minutes in both $\mathrm{C} x 40^{+/+}$and $C x 40^{-/-}$lungs, yet the magnitude of the HPV response was substantially reduced in $\mathrm{C} x 40^{--}$compared with $C x 40^{+/+}$lungs. As a result, the slope of the nonlinear pressure-flow curve at the intercept with the abscissa, reflecting the intrinsic vascular resistance $\left(\mathrm{R}_{0}\right)$, increased markedly with hypoxia in $\mathrm{C} x 40^{+/+}$, but not $\mathrm{C} x 40^{-/-}$, lungs (Figure $2 \mathrm{~B}$ ). Group data analyses confirmed that the hypoxia-induced increase in PAP $(\triangle \mathrm{PAP})$
$\mathrm{Cx} 43$ was expressed in both lung arterioles and - although, again, more irregularly - capillaries (Figure 3A). However, neither Cx43 immunostaining nor its expression or Ser368 phosphorylation state differed between $\mathrm{C} x 40^{+/+}$and $\mathrm{C} x 40^{-/-}$lungs (Figure 3, A and B). Notably, inhibition of $\mathrm{Cx} 43$ by gap $27^{43}(200 \mu \mathrm{M})$ also attenuated the HPV response, albeit without reaching statistical significance (Figure 3C). Importantly, the combination of both gap $27^{40}$ and gap $27^{43}$ blocked HPV to a significantly greater extent than did either mimetic peptide alone. While these data did not rule out potential relevance of $\mathrm{Cx} 43$ in HPV, they clearly demonstrated that the role of $\mathrm{Cx} 40$ described herein does not relate to secondary changes in Cx43-mediated gap junctional communication.

To test the relevance of $\mathrm{Cx} 40$ for pulmonary V/Q matching in vivo, we induced $\mathrm{V} / \mathrm{Q}$ mismatches in anesthetized mice by tracheal instillation of saline droplets, resulting in regional occlusion of alveolar ventilation. $\mathrm{C} x 40^{+/+}$mice responded with a modest decline in arterial partial pressure of oxygen $\left(\mathrm{PaO}_{2}\right)$, whereas the same maneuver resulted in considerable hypoxemia in $\mathrm{C} x 40^{-/-}$mice (Figure 4A), demonstrating their inability to redistribute blood flow to better ventilated lung areas. Notably, $\mathrm{PaO}_{2}$ was already lower in $\mathrm{C} x 40^{-/-}$versus $\mathrm{C} x 40^{+/+}$mice prior to saline instillation, suggestive of a higher basal shunt in the absence of $\mathrm{Cx} 40$. Moreover, the reduction in $\mathrm{PaO}_{2}$ during the first 2 minutes after saline instillation was significantly larger in $C \times 40^{-/-}$compared with $\mathrm{C} x 40^{+/+}$ mice $(34.8 \pm 4.4$ vs. $14.2 \pm 3.1 \mathrm{mmHg} ; P<0.01)$. Stepwise reductions in the inspiratory fraction of oxygen $\left(\mathrm{FIO}_{2}\right)$ from 0.21 to 0.19 were well tolerated in $\mathrm{C} x 40^{+/+}$mice, but resulted in a dramatic drop in arterial hemoglobin oxygen saturation $\left(\mathrm{SaO}_{2}\right)$ in $\mathrm{C} x 40^{-/-}$mice

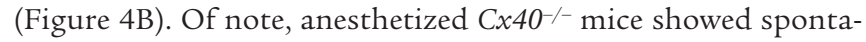
neous episodes of arterial desaturation even during normoxic 

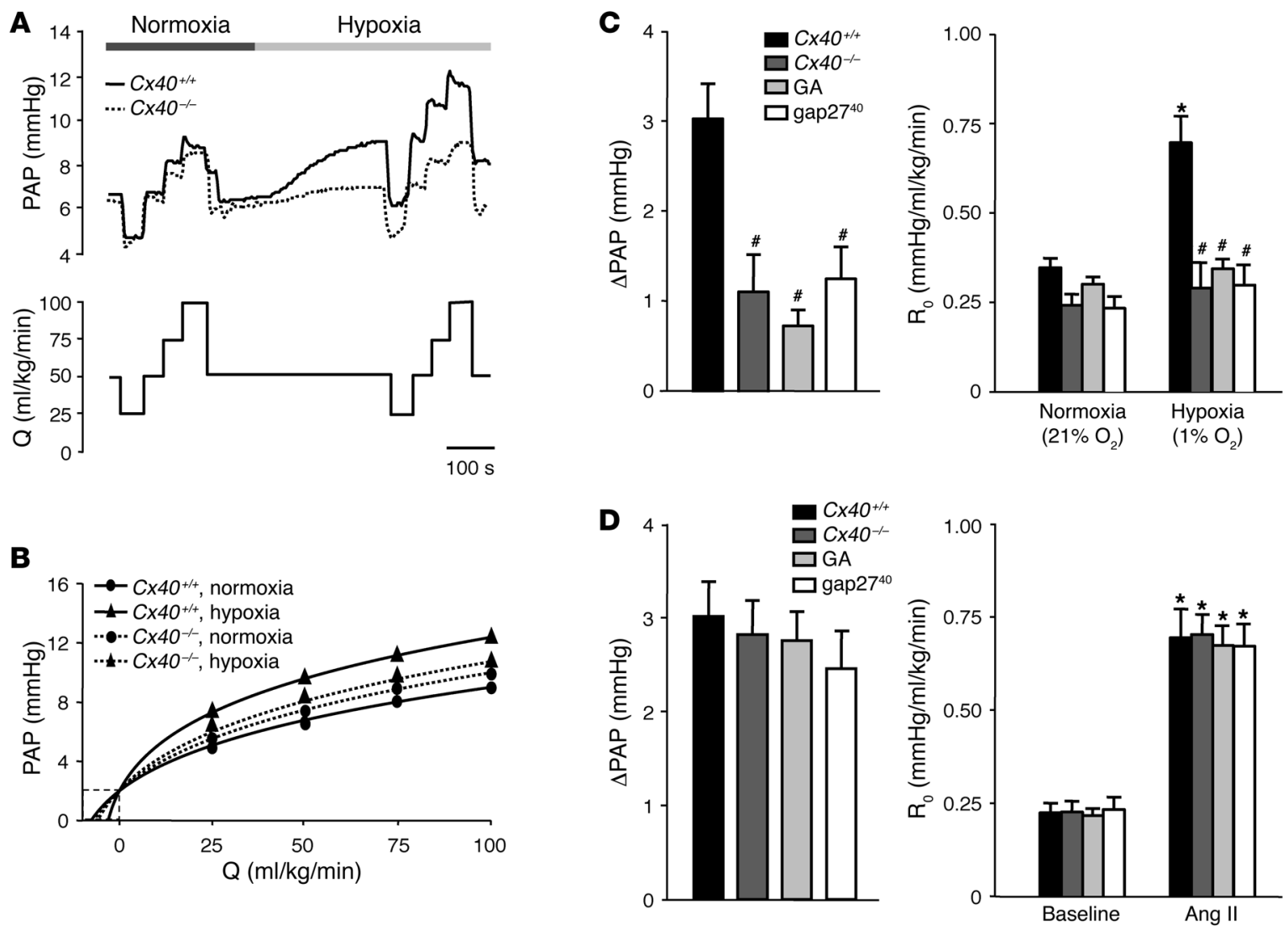

\section{Figure 2}

Cx40 is required for an intact HPV response. (A) Representative tracings of PAP in isolated perfused lungs of $C \times 40^{+/+}$and $\mathrm{Cx} 40^{-/-}$mice obtained during stepwise changes in lung perfusion $(\mathrm{Q})$ at normoxia $\left(21 \% \mathrm{O}_{2}\right)$ or hypoxia $\left(1 \% \mathrm{O}_{2}\right)$. Note the attenuated $\mathrm{HPV}$ response in $\mathrm{Cx} 40^{-/-}$mice. (B) Nonlinear regression analysis according to the distensible vessel model yielded representative pressure-flow curves for lungs of $\mathrm{C} x 40^{+/+}$ and $\mathrm{C}_{4} 40^{-/-}$mice at normoxia and hypoxia. The pressure at $0 \mathrm{ml} / \mathrm{kg} / \mathrm{min}$ flow $(\mathrm{Q})$ reflects left arterial pressure of $2 \mathrm{mmHg}$, while the slope of the pressure-flow curve at $0 \mathrm{ml} / \mathrm{kg} / \mathrm{min}$ flow reflects $\mathrm{R}_{0}$. (C) Group data showing acute HPV response, determined as $\triangle P A P$ and as $R_{0} 10$ minutes after hypoxia onset versus normoxia, in untreated isolated perfused lungs of $\mathrm{Cx} 40^{+/+}$and $\mathrm{Cx} 40^{-/-}$mice and in lungs of $\mathrm{Cx} 40^{+/+}$mice treated with $18 \alpha$-glycyrrhetinic acid $(\mathrm{GA} ; 50 \mu \mathrm{M})$ or gap2 $7^{40}(200 \mu \mathrm{M})$. (D) Group data $(n=5$ lungs each) showing acute HPV response to Ang II (1 $\mu \mathrm{g}$ bolus infusion), determined as $\triangle \mathrm{PAP}$ and as $\mathrm{R}_{0}$ versus baseline, in untreated isolated perfused lungs of $C \times 40^{+/+}$and $C \times 40^{-/-}$mice and in lungs of $C \times 40^{+/+}$ mice treated with $18 \alpha$-glycyrrhetinic acid or gap2 740 . ${ }^{*} P<0.05$ vs. normoxia or baseline control; $\# P<0.05$ vs. untreated $C \times 40^{+/+}$.

ventilation that were rapidly reversible by recruitment maneuvers with $30 \mathrm{cmH}_{2} \mathrm{O}$ airway pressure, which suggests that $\mathrm{C} x 40^{-1-}$ mice were not able to redistribute pulmonary blood flow adequately in the case of spontaneous atelectases. To directly demonstrate the inability of $\mathrm{Cx}_{40^{--}}$mice to redistribute blood flow from hypoxic to normoxic lung areas, we quantified regional lung perfusion by the fluorescent microsphere technique in mice subjected to 1-lung ventilation. In line with an intact HPV response, blood flow to the ventilated lung was approximately twice that to the nonventilated lung in $\mathrm{C} x 40^{+/+}$mice (Figure $4 \mathrm{C}$ ). Yet in $\mathrm{C} x 40^{-/-}$mice, the perfusion difference between ventilated and nonventilated lung was reduced roughly two-thirds, demonstrating V/Q mismatching.

To further substantiate the notion that the relevance of $\mathrm{Cx} 40$ in HPV relates to its role as an endothelial gap junctional molecule, we tested the HPV response in lungs of mice with endothelial-specific deletion of $\mathrm{Cx} 40$ (Tie2 $\mathrm{Cre} \mathrm{C}^{+} \mathrm{C} 40^{\mathrm{fl} / \mathrm{fl}} \mathrm{ApoE^{-/- }}$ mice). Similar to $\mathrm{C} x 40^{-/-}$ mice, hypoxia-induced $\Delta \mathrm{R}_{0}$ was largely blocked in isolated lungs of Tie $2 \mathrm{Cre}^{+} \mathrm{C} \times 40^{f / f l} \mathrm{ApoE^{-/- }}$ mice, while it was unabated in correspond-

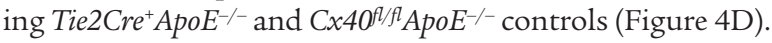

Cx40 deficiency attenuates chronic hypoxic pulmonary bypertension. Next, we tested whether $\mathrm{Cx} 40$ is also essentially required for the lung vascular adaptation response to chronic hypoxia. In $\mathrm{C} x 40^{-/-}$ mice, the characteristic increases in right ventricular systolic pressure and right ventricular weight relative to septal and left ventricular weight (Fulton index) in response to 5 weeks of hypoxia were almost completely abrogated (Figure 5, A and B). Likewise, muscularization of small pulmonary arterioles, as seen in chronic hypoxic $\mathrm{C} x 40^{+/+}$mice, was largely absent in $\mathrm{C} x 40^{-/-}$mice (Figure 5, $\mathrm{C}$ and $\mathrm{D})$, which suggests that $\mathrm{Cx} 40$ not only is required for an intact HPV, but also plays a critical role in lung vascular remodeling and pulmonary hypertension in response to chronic hypoxia.

Cx40 propagates hypoxia-induced endothelial membrane depolarization. In the systemic circulation, conducted responses are realized by the rapid propagation of membrane potential $\left(E_{\mathrm{m}}\right)$ changes via intercellular gap junctions (19). To test whether $\mathrm{Cx} 40$ mediates similar signal propagation in HPV, we monitored the effects of hypoxia on endothelial $E_{\mathrm{m}}$ in isolated lungs of $\mathrm{C} x 40^{+/+}$and $\mathrm{C} x 40^{-/-}$mice. Within seconds, a switch from normoxic to hypoxic ventilation caused a 
A
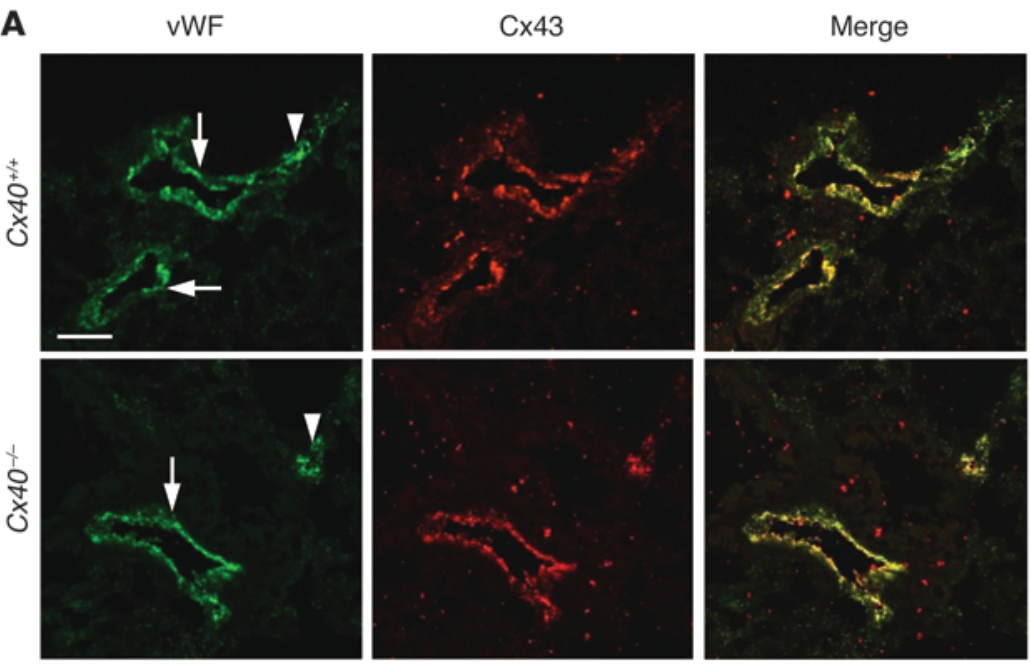

B
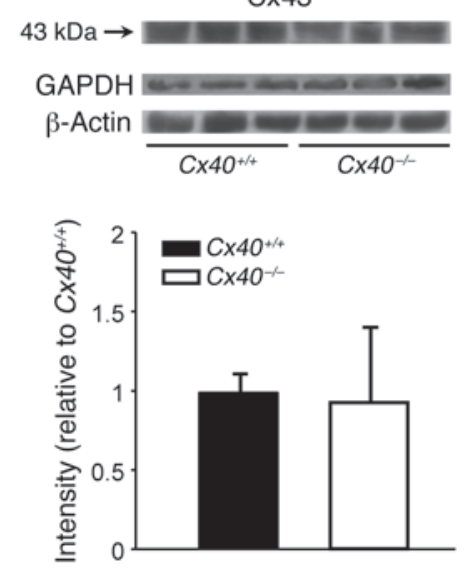
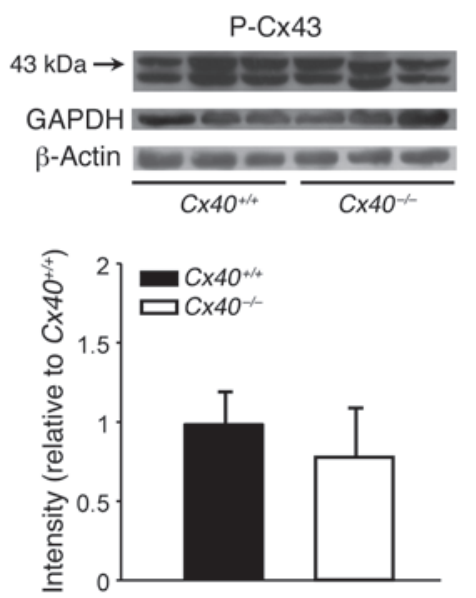

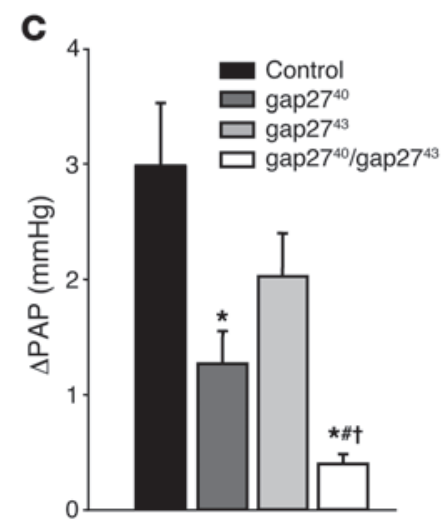

\section{Figure 3}

The role of Cx40 in HPV is independent of Cx43. (A) Expression of VWF (green) and Cx43 (red) and merged images for pulmonary arterioles (arrows) and capillaries (arrowhead) of $\mathrm{C} \times 40^{+/+}$and $\mathrm{C} \times 40^{-/-}$mice. Scale bar: $50 \mu \mathrm{m}$. (B) Representative Western blots and quantification showing expression and Ser368 phosphorylation of $\mathrm{Cx} 43$ in fresh lung homogenate from $\mathrm{Cx} 40^{+/+}$and $\mathrm{C} \times 40^{-/-}$mice. GAPDH and $\beta$-actin are shown as loading controls. (C) Group data ( $n=5$ lungs each) showing acute HPV response, determined as $\triangle$ PAP 10 minutes after onset of hypoxia (1\% $\mathrm{O}_{2}$ ) versus normoxia $\left(21 \% \mathrm{O}_{2}\right)$ in isolated perfused lungs of untreated $C \times 40^{+/+}$mice and of $C \times 40^{+/+}$mice treated with gap2740 $(200 \mu \mathrm{M})$, gap2743 $(200 \mu \mathrm{M})$, or both in combination. ${ }^{\star} P<0.05$ vs. control; $\# P<0.05$ vs. gap $27^{40}$; $\uparrow P<0.05$ vs. gap $27^{43}$.

marked increase in endothelial di-8-ANEPPS fluorescence in both alveolar capillaries and upstream arterioles of $\mathrm{C} x 40^{+/+}$lungs (Figure $6 \mathrm{~A}$ ), indicative of endothelial depolarization. In alveolar capillaries, this depolarization occurred in advance of corresponding changes in neighboring arterioles (Figure 6B). In isolated lungs of $\mathrm{C} x 40^{-/-}$ mice, baseline endothelial di-8-ANEPPS fluorescence in arterioles and capillaries did not differ from those of $\mathrm{C} x 40^{+/+}$lungs (Figure $6 \mathrm{C}$ ). Yet hypoxia caused endothelial depolarization only in alveolar capillaries, while the increase in di-8-ANEPPS fluorescence was largely abrogated in upstream arterioles of $\mathrm{C} \times 40^{-/-}$lungs (Figure 6, A and D). These findings identified a critical role for $\mathrm{Cx} 40$ in the propagation of hypoxia-induced endothelial depolarization from the level of the alveolar capillaries to the upstream arterioles.

In order to evaluate the magnitude of endothelial depolarization in response to hypoxia, we calibrated the di-8-ANEPPS imaging technique by perfusing $\mathrm{C} x 40^{+/+}$lungs with different $\mathrm{K}^{+}$con- centrations $\left(\left[\mathrm{K}^{+}\right]\right.$; Figure $\left.6 \mathrm{E}\right)$. Linear extrapolation of the results from the calibration experiments revealed that the increases in di-8-ANEPPS fluorescence in response to hypoxia in arterioles and capillaries of $\mathrm{C} x 40^{+/+}$lungs approximately equaled the effects of lung perfusion with 13.5 and $8.6 \mathrm{mM}\left[\mathrm{K}^{+}\right]$solution, respectively. Assuming a baseline $E_{\mathrm{m}}$ of $-86.5 \mathrm{mV}$ for lung perfusion with $5.9 \mathrm{mM}\left[\mathrm{K}^{+}\right]$, these findings indicate a hypoxia-induced endothelial depolarization by $11.9 \mathrm{mV}$ in capillaries and $24.0 \mathrm{mV}$ in arterioles, as calculated by the Nernst relationship. The functional relevance of this depolarization in HPV was highlighted by the finding that the characteristic $\triangle \mathrm{PAP}$ in response to hypoxia was blocked when isolated lungs were perfused with a buffer solution containing $20 \mathrm{mM}\left[\mathrm{K}^{+}\right]$(Figure 6F). Analogous to the effects of gap junction uncouplers, this inhibition by a depolarizing buffer was specific for hypoxia-induced vasoconstriction, while the pressure response to Ang II was enhanced. 
A
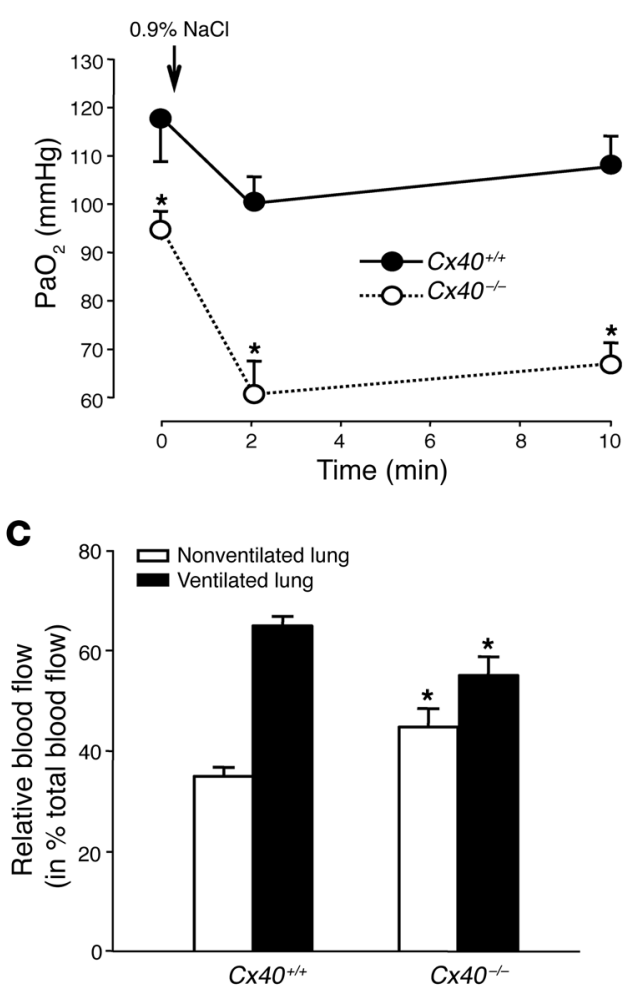
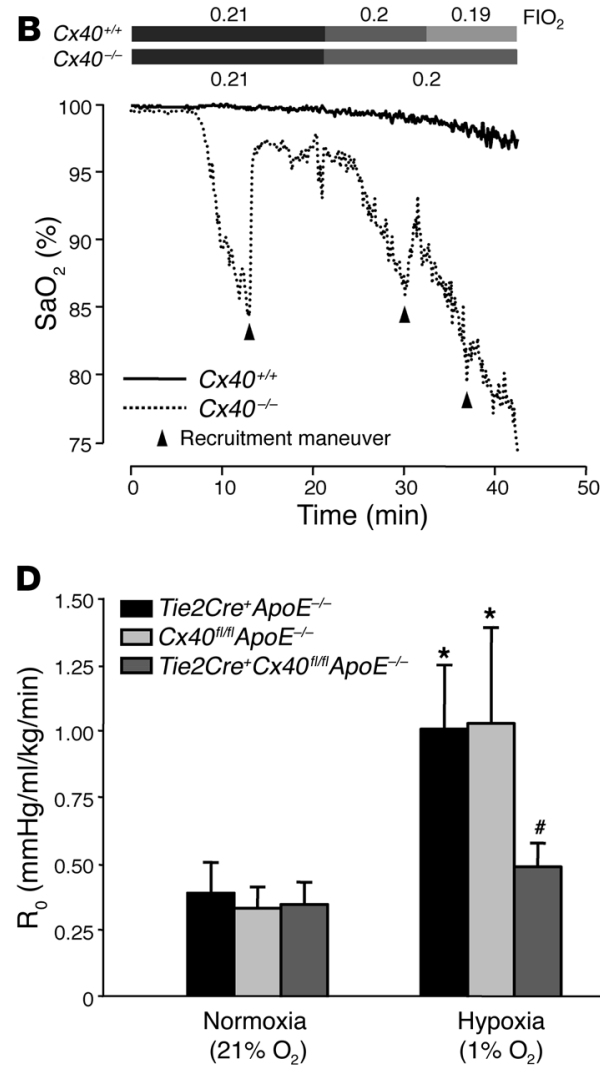

Figure 4

Cx40 optimizes oxygenation and V/Q matching in hypoxic lungs in vivo. (A) Group data $(n=5$ lungs each) showing arterial $\mathrm{PaO}_{2}$ in anesthetized $\mathrm{C} \times 40^{+/+}$and $\mathrm{C} \times 40^{-/-}$mice prior to (0 minutes) and after partial occlusion of larger airways by tracheal instillation of $25 \mu \mathrm{l}$ saline. $\mathrm{PaO}_{2}$ was already significantly lower in $\mathrm{Cx} 40^{-/-}$versus $\mathrm{Cx} 40^{+/+}$mice at baseline; this difference was further amplified after induction of $\mathrm{V} / \mathrm{Q}$ mismatches by saline instillation. ${ }^{\star} P<0.05 \mathrm{vs}$. $C \times 40^{+/+}$. (B) Representative tracings (of 5 replicates) showing $\mathrm{SaO}_{2}$ in anesthetized $\mathrm{C} \times 40^{+/+}$and $\mathrm{C} \times 40^{-/-}$mice during stepwise decrements in $\mathrm{FIO}_{2}$ starting at 0.21 . In the case of sudden $\mathrm{SaO}_{2}$ decrements, recruitment maneuvers were performed (arrowheads) to counteract atelectases. (C) Group data ( $n=5$ lungs each) showing relative blood flow (percent total pulmonary blood flow) to the nonventilated right and ventilated left lung during 1-lung ventilation in $\mathrm{C} \times 40^{+/+}$and $C \times 40^{-/-}$mice, assessed by fluorescent microsphere technique. ${ }^{*} P<0.05$ vs. $\mathrm{C} \times 40^{+/+}$. (D) Group data ( $n=5$ lungs each) showing acute HPV response, determined as $\mathrm{R}_{0} 10$ minutes after hypoxia $\left(1 \% \mathrm{O}_{2}\right)$ onset versus normoxia $\left(21 \% \mathrm{O}_{2}\right)$, in isolated perfused lungs of Tie $2 \mathrm{Cre}+\mathrm{C} \times 4 \mathrm{O}^{\mathrm{fl} / \mathrm{fl}}$

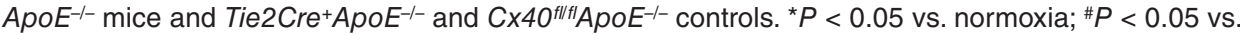

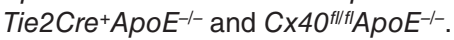

In PASMCs, hypoxia-induced membrane depolarization has been attributed to the inhibition of oxygen-sensitive, voltagegated $\mathrm{K}^{+}\left(\mathrm{K}_{\mathrm{v}}\right)$ channels, of which $\mathrm{K}_{\mathrm{v}} 1.5$ and $\mathrm{K}_{\mathrm{v}} 2.1$ are considered particularly relevant (20-22). To test the potential involvement of these channels in the hypoxic response of lung microvascular endothelial cells, we determined their expression and functionality in the intact mouse lung preparation. Western blot analysis revealed expression of both $\mathrm{K}_{\mathrm{v}} 1.5$ and $\mathrm{K}_{\mathrm{v}} 2.1$ in freshly isolated pulmonary endothelial cells as well as in nonpulmonary endothelial cells (i.e., HUVECs; Figure 6G). Inhibition of $\mathrm{K}_{\mathrm{v}}$ channels by 4-aminopyridine (10 $\mathrm{mM})$, which constricts lung vessels and blocks subsequent HPV (23), caused endothelial membrane depolarization in pulmonary microvessels of both $\mathrm{C} x 40^{+/+}$and $\mathrm{C} \times 40^{-/-}$mice, to an extent similar to that of hypoxia in $\mathrm{C} x 40^{+/+}$ mouse pulmonary arterioles (Figure $6 \mathrm{H}$ ), thus attesting to the functional integrity of endothelial $\mathrm{K}_{\mathrm{v}}$ channels.

Endothelial $\left[\mathrm{Ca}^{2+}\right]_{i}$ signaling is required for $H P V$. As lung microvascular endothelial cells express $\alpha_{1 \mathrm{G}}$ subtype $\mathrm{T}$ type voltage-dependent $\mathrm{Ca}^{2+}$ channels (VDCCs) (15), membrane depolarization may trigger an increase in the endothelial cytosolic $\mathrm{Ca}^{2+}$ concentration $\left(\left[\mathrm{Ca}^{2+}\right]_{i}\right)$, a notion that we tested by real-time imaging of the endothelial $\left[\mathrm{Ca}^{2+}\right]_{\mathrm{i}}$ response to hypoxia. In lungs from $\mathrm{C} \times 40^{+/+}$mice, hypoxia induced a distinct endothelial $\Delta\left[\mathrm{Ca}^{2+}\right]_{i}$ in both lung capillaries and arterioles (Figure 7, A and B). In lungs from $C \times 40^{-1-}$ mice, this endothelial $\left[\mathrm{Ca}^{2+}\right]_{\mathrm{i}}$ response to hypoxia was conserved in alveolar capillaries, but largely absent in corresponding upstream arterioles. Inhibition of the endothelial $\left[\mathrm{Ca}^{2+}\right]_{\mathrm{i}}$ response to hypoxia in both lung capillaries and arterioles of $\mathrm{C} x 40^{+/+}$mice by the VDCC blocker mibefradil $(10 \mu \mathrm{M})$ identified VDCCs as a functional link between membrane depolarization and endothelial $\left[\mathrm{Ca}^{2+}\right]_{\mathrm{i}}$ signaling (Figure 7C). This notion was substantiated by the finding that endothelial $\Delta\left[\mathrm{Ca}^{2+}\right]_{i}$ in response to hypoxia in both capillaries and arterioles was lost in lungs of mice deficient in the $\alpha_{1 \mathrm{G}}$ subtype $\mathrm{T}$ type channel (Cacna1g $g^{--}$mice), while the depolarization response was unaffected (Figure 7, D and E).

Next, we tested whether the endothelial $\left[\mathrm{Ca}^{2+}\right]_{\mathrm{i}}$ response to hypoxia was functionally relevant in HPV. We perfused lungs under absorptive conditions (24) with the intracellular $\mathrm{Ca}^{2+}$ chelator BAPTA-AM $(40 \mu \mathrm{M})$ to selectively block endothelial $\left[\mathrm{Ca}^{2+}\right]_{\mathrm{i}}$ signaling. BAPTA-AM perfusion almost completely blocked HPV in lungs of $\mathrm{C} x 40^{+/+}$mice (Figure 7F), yet did not attenuate the pulmonary vasoconstrictor response to Ang II $(1 \mu \mathrm{g}$; Figure $7 \mathrm{G})$, which confirmed that endothelial, but not smooth muscle, $\mathrm{Ca}^{2+}$ was chelated with the protocol used. Furthermore, BAPTA-AM did not attenuate endothelial depolarization in response to hypoxia (Figure $7 \mathrm{H}$ ), which substantiates the notion that in the endothelial response to hypoxia, $\Delta E_{\mathrm{m}}$ occurs upstream of $\Delta\left[\mathrm{Ca}^{2+}\right]_{\mathrm{i}}$.

$c P L A_{2}$ regulates $H P V$. The next step was to identify the signaling mechanism by which the endothelial $\mathrm{Ca}^{2+}$ signal may evoke a contractile response in the juxtaposed PASMCs. A presumptive signaling pathway in this context is the generation of arachidonic acid (AA) metabolites as vasoactive lipid messengers in endothelial cells via the $\mathrm{Ca}^{2+}$-dependent activation of cytosolic phospholipase $\mathrm{A}_{2}$ $\left(\mathrm{cPLA}_{2}\right)(25)$. This hypothesis is particularly attractive in light of recent studies that suggest functional relevance for the AA metabo- 


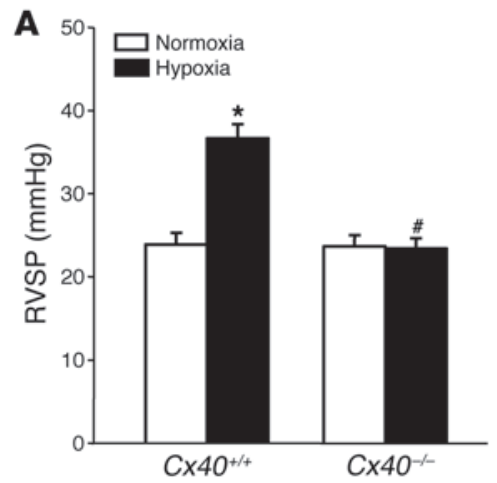

B
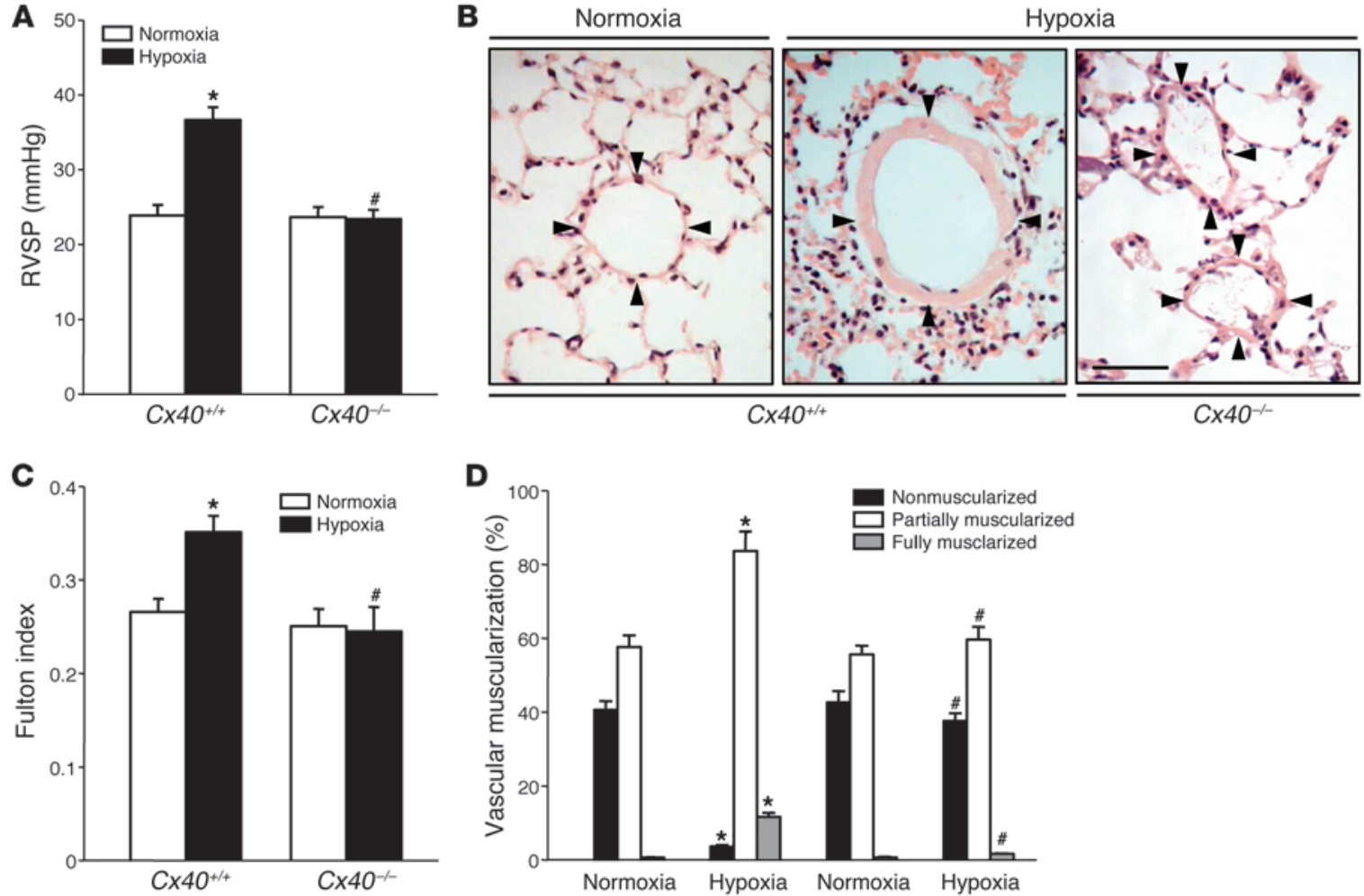

D

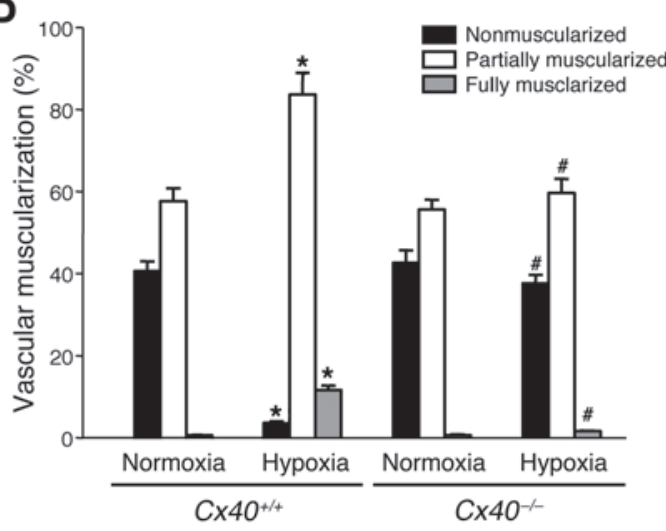

\section{Figure 5}

Cx40 deficiency attenuates chronic hypoxic pulmonary hypertension. Group data showing (A) right ventricular systolic pressure (RVSP) and (B) right ventricular weight relative to septal and left ventricular weight (Fulton index) in $\mathrm{C} \times 40^{+/+}$and $\mathrm{Cx} 40^{-/-}$mice housed in either normoxia $\left(21 \% \mathrm{O}_{2}\right)$ or hypoxia $\left(10 \% \mathrm{O}_{2}\right)$ for 5 weeks. (C) Representative images of H\&E-stained lung sections showing pulmonary arterioles (denoted by 4 arrowheads each). Scale bar: $50 \mu \mathrm{m}$. (D) Group data ( $n=8$ mice each) showing degree of vascular muscularization in pulmonary arterioles 20-50 $\mu \mathrm{m}$ in diameter, expressed as proportion of non-, partially, or fully muscularized vessels, in lungs from normoxic and hypoxic $C \times 40^{+/+}$and $C \times 40^{-1-}$ mice. ${ }^{*} P<0.05$ vs. normoxia; $\# P<0.05$ vs. $C \times 40^{+/+}$.

lites epoxyeicosatrienoic acids (EETs) in HPV (26). As activation of $\mathrm{cPLA}_{2}$ involves $\mathrm{Ca}^{2+}$-dependent translocation of the enzyme from the cytosolic cell fraction to the cell membrane and the nuclear envelope (27), we applied indirect immunofluorescence imaging in endothelial cells of the isolated perfused lung and in cultured pulmonary arterial endothelial cells (PAECs) to test whether $\mathrm{CPLA}_{2}$ translocates in response to hypoxia. Due to pharmacological membrane permeabilization and subsequent loss of unbound, cytoplasmic $\mathrm{CPLA}_{2}$, the applied immunofluorescence assay stains exclusively for translocated, membrane-bound cPLA 2 . While translocated $\mathrm{CPLA}_{2}$ was hardly detectable under normoxic conditions, hypoxia induced a marked and rapid ( $\leq 10$ minutes) translocation of $\mathrm{CPLA}_{2}$ in endothelial cells of intact mouse lungs in situ and in PAECs in vitro (Figure 8, A and B). Confocal microscopic imaging in PAECs revealed that $\mathrm{CPLA}_{2}$ translocated primarily to the perinuclear region (nuclear envelope) and, to a lesser extent, to the plasma membrane. Pretreatment of isolated $\mathrm{C} x 40^{+/+}$lungs with the specific $\mathrm{CPLA}_{2}$ inhibitor arachidonyl trifluoromethyl ketone $\left(\mathrm{AACOCF}_{3}\right.$; $1 \mu \mathrm{M}$ ) largely blocked $\triangle \mathrm{PAP}$ in response to hypoxia (Figure 9A), highlighting the functional relevance of $\mathrm{CPLA}_{2}$ activation in HPV. Conversely, pretreating lungs with palmitoyl trifluoromethyl ketone $\left(\mathrm{PACOCF}_{3} ; 1 \mu \mathrm{M}\right)$, an inhibitor of the $\mathrm{Ca}^{2+}$-independent phospholipase $\mathrm{A}_{2}\left(\mathrm{iPLA}_{2}\right)$, had no significant effect on the HPV response. As previous studies had identified EETs as AA metabolites with a critical role in HPV (26), we next tested the role of $\mathrm{Cx} 40$ in hypoxia-induced EET generation in intact mouse lungs. We quantified levels of 8,9-EET, 11,12-EET, and 14,15-EET at normoxia and after 10 minutes of hypoxia (i.e., at the approximate peak of the HPV response; ref. 28) in isolated perfused lungs. In line with their proposed role as mediators of HPV (26), pulmonary levels of 11,12-EET and 14,15-EET increased during hypoxia in $\mathrm{C} x 40^{+/+}$ mice (Figure 9, B and C), whereas the concentration of 8,9-EET decreased (data not shown). In $\mathrm{C} x 40^{-/-}$mice, hypoxia-induced stimulation of 11,12-EET and 14,15-EET production was not evident, even though they expressed higher baseline levels of both regioisomers. Perfusion with exogenous 11,12-EET caused similar $\triangle \mathrm{PAP}$ in $\mathrm{C} \times 40^{+/+}$and $\mathrm{C} \times 40^{-/-}$mouse lungs (Figure 9D), which confirmed that EETs act as vasoconstrictive mediators in the pulmonary circulation and that this response itself does not depend on $\mathrm{Cx} 40$.

\section{Discussion}

The present study reports what we believe to be a fundamentally new concept for the mechanism of HPV in intact lungs (Figure 10). In contrast to prevailing paradigms, our data revealed a pivotal role for the pulmonary endothelium in HPV, in that it conducts a hypoxic response retrogradely via Cx40-containing gap 
A
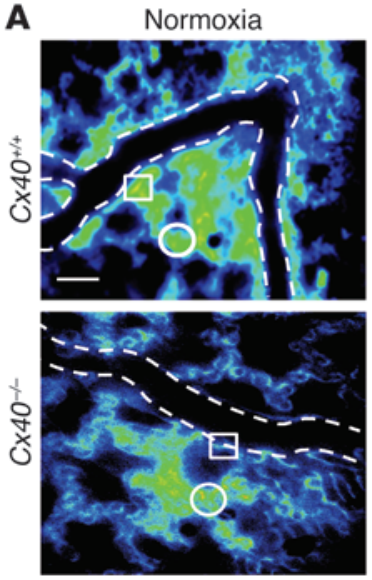

C
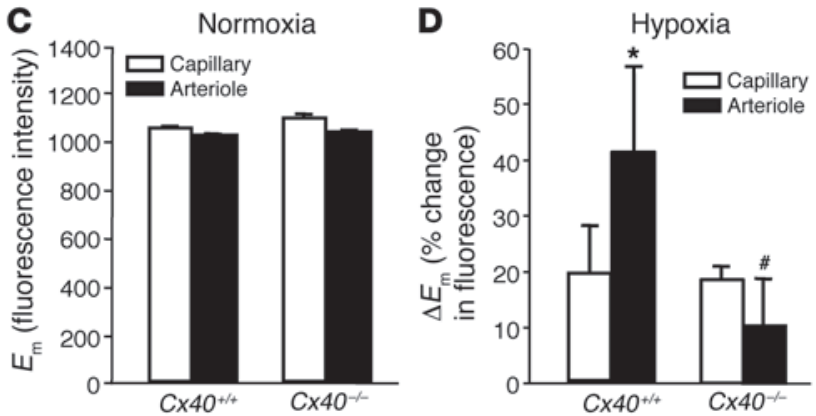

Hypoxia
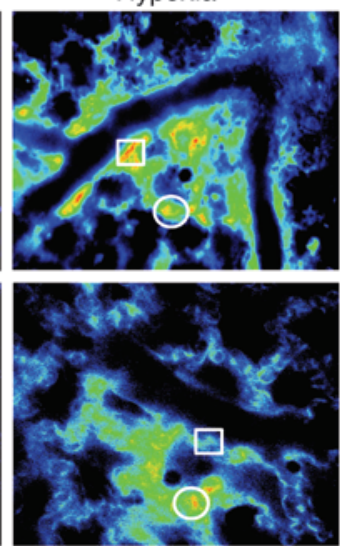

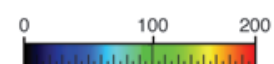

Fluorescence intensity
B

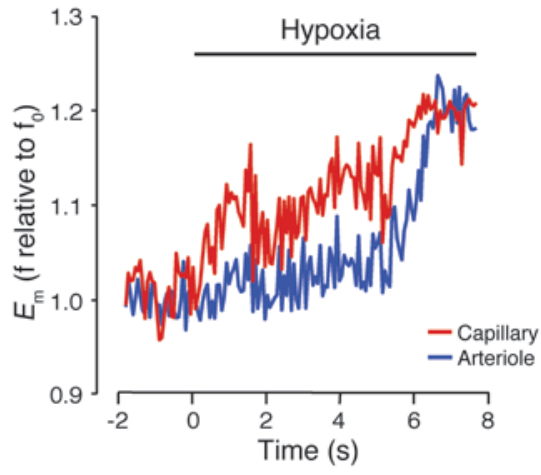

E

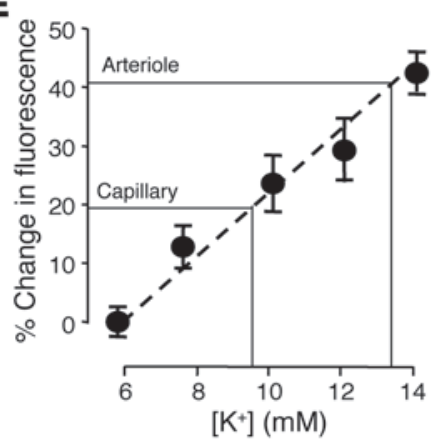

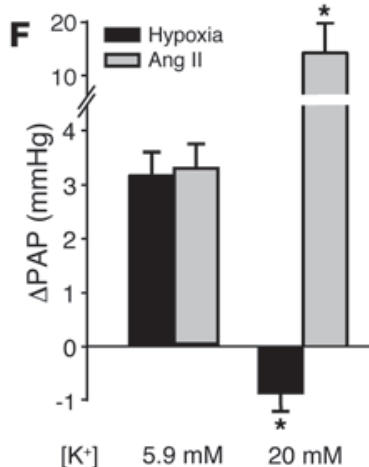

G

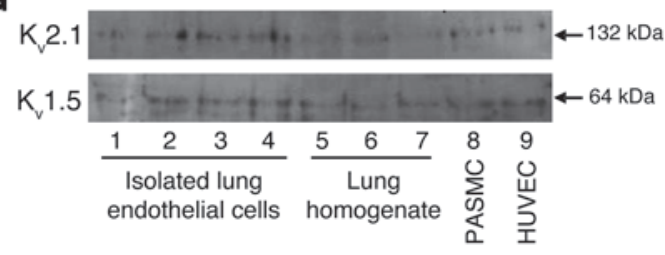

H

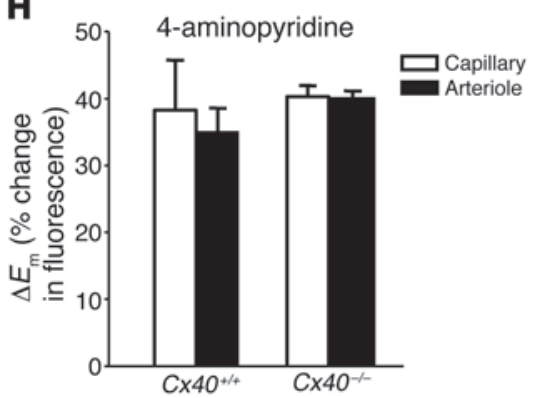


A

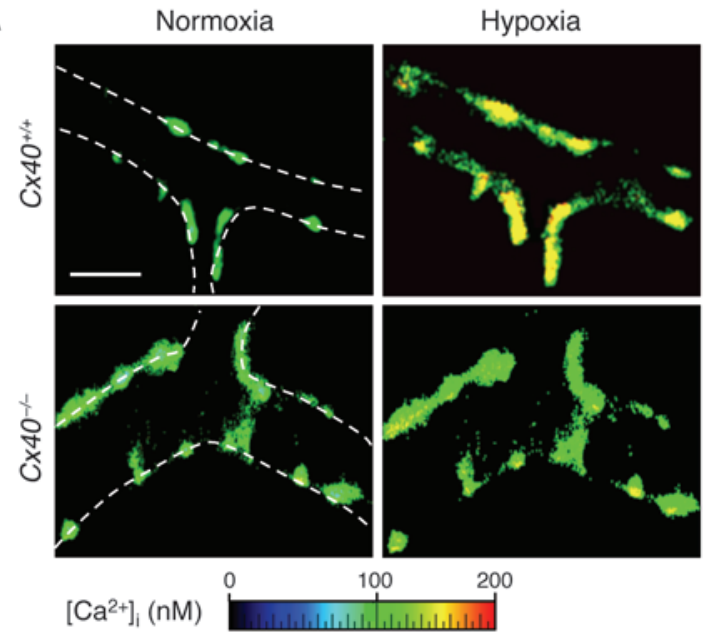

B

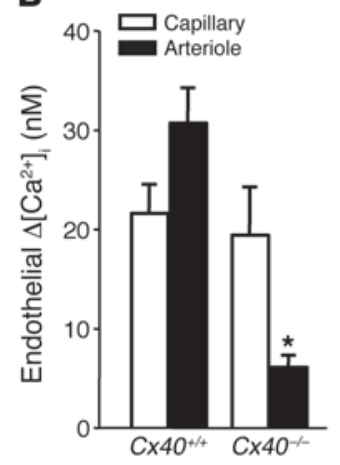

C

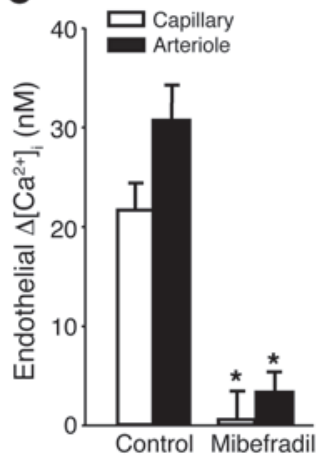

D

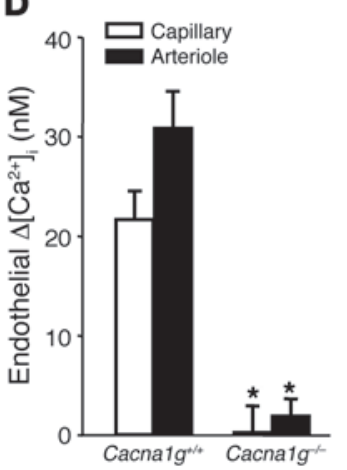

E

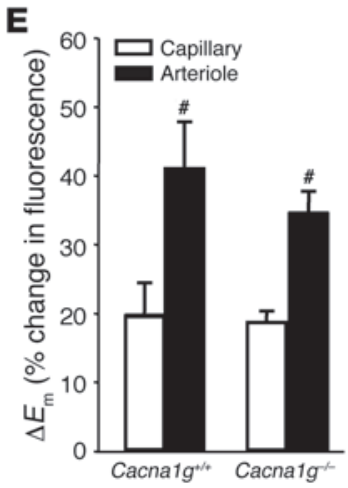

F

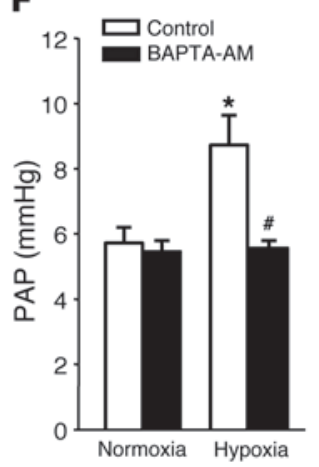

G

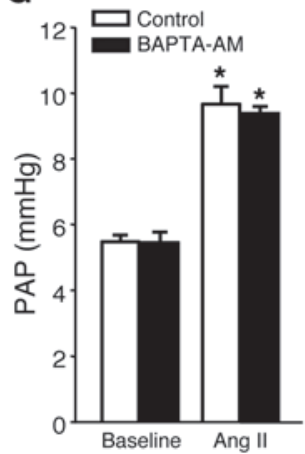

H

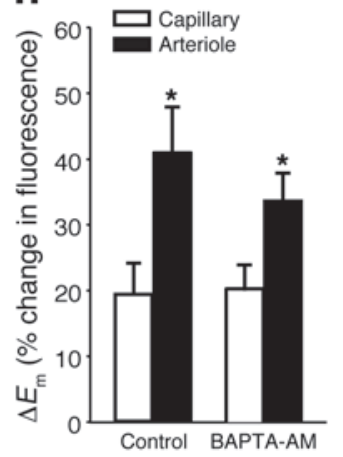

Figure 7

Role of endothelial $\left[\mathrm{Ca}^{2+}\right]_{i}$ in acute HPV. (A) Representative images (of 5 replicates) of fura-2-loaded lung arterioles showing endothelial [Ca $\left.{ }^{2+}\right]_{i}$ at normoxia $\left(21 \% \mathrm{O}_{2}\right)$ and after 10 minutes of hypoxia $\left(1 \% \mathrm{O}_{2}\right)$ in $\mathrm{C} \times 40^{+/+}$and $\mathrm{Cx} 40^{-/-}$lungs. Vessel margins are denoted by dotted lines. Scale bar: $50 \mu \mathrm{m}$. Group data ( $n=5$ lungs each) show endothelial $\Delta\left[\mathrm{Ca}^{2+}\right]_{i}$ in response to acute hypoxia in pulmonary capillaries and arterioles of (B) $\mathrm{C} \times 40^{+/+}$and $\mathrm{Cx} 40^{-/-}$mice or (C) $\mathrm{C} \times 40^{+/+}$lungs in the absence (control) or presence of the VDCC blocker mibefradil $(10 \mu \mathrm{M})$. ${ }^{*} P<0.05$ vs. $C \times 40^{+/+}$or control. Group data ( $n=5$ lungs each) showing (D) endothelial $\Delta\left[\mathrm{Ca}^{2+}\right]_{\mathrm{i}}$ or $(\mathrm{E}) \Delta E_{\mathrm{m}}$ in response to acute hypoxia in capillaries and arterioles of Cacna1 $\mathrm{g}^{+/+}$and Cacna1 $\mathrm{g}^{-/-}$lungs. ${ }^{*} P<0.05$ vs. Cacna1 $\mathrm{g}^{+/+} ; \# P<0.05$ vs. capillary. Group data $(n=5$ lungs each) showing PAP in isolated perfused $\mathrm{C} \times 40^{+/+}$lungs (F) at normoxia and after 10 minutes of hypoxia or (G) at baseline and after Ang II (1 $\mu \mathrm{g}$ bolus) in control lungs or after endothelial $\mathrm{Ca}^{2+}$ chelation by BAPTA-AM $(40 \mu \mathrm{M})$. ${ }^{*} P<0.05$ vs. normoxia or baseline; ${ }^{*} P<0.05$ vs. control. (H) Group data $(n=5$ lungs each) showing endothelial $\Delta E_{\mathrm{m}}$ in response to acute hypoxia in pulmonary capillaries and arterioles in the absence (control) or presence of BAPTA-AM. * $P<0.05$ vs. capillary.

pose that endothelial $\mathrm{Ca}^{2+}$ signaling is essential for an intact HPV response, probably in that it causes generation of vasoconstrictive AA metabolites such as EETs via activation of cPLA 2 . Notably, the critical role of $\mathrm{Cx} 40$ in hypoxia extends beyond the acute HPV response, as $\mathrm{C} x 40^{-1-}$ mice were largely protected from chronic hypoxic pulmonary hypertension and vascular remodeling. The emerging recognition of the endothelium as an important regulator of HPV and the implication of a conducted response provide what we believe to be a novel view of HPV, and - as discussed below - may provide a mechanistic explanation for the impairment of HPV in various pathophysiological conditions.

Previous studies in HPV have focused predominantly on the PASMC as both sensor and effector cell, for which a signaling network of rapidly growing complexity has been identified (1, 29). In contrast, the contribution of the endothelium to the initial HPV response is generally considered insignificant, given that (a) hypoxia causes contraction of isolated PASMCs in vitro in the absence of endothelial cells (30) and that (b) the acute HPV response is unabated or even enhanced after endothelial denudation in isolated pulmonary arterial vessel rings $(23,31,32)$. While isolated PASMCs and vessel rings have been indispensable tools for the study of hypoxic signaling in smooth muscle cells, these techniques fail to address aspects of HPV that relate to the morphological characteristics of the intact pulmonary vasculature. As HPV responds to changes in alveolar gas composition rather than in pulmonary arterial blood, the oxygen sensor should ideally be located either within the alveolocapillary unit or in vessels downstream thereof (3). Yet HPV is restricted to lung vessels larger than $30 \mu \mathrm{m}$ in diameter (6) and is predominantly localized in mediumsized pulmonary arterioles of 100-500 $\mu \mathrm{m}$ (33). Electron microscopic studies show that these arterioles are not in direct proximity to the alveolar space, but are embedded in a sheath of parenchymal tissue with sparse, nonalveolar capillaries (34). Based on these considerations, we hypothesized that sensor and effector in HPV 
A
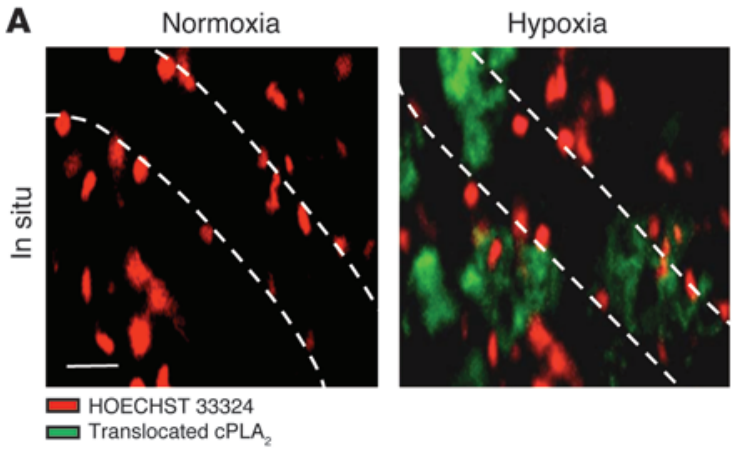

$\square$ Translocated cPLA

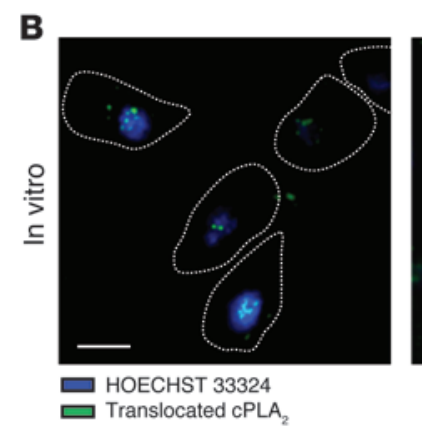

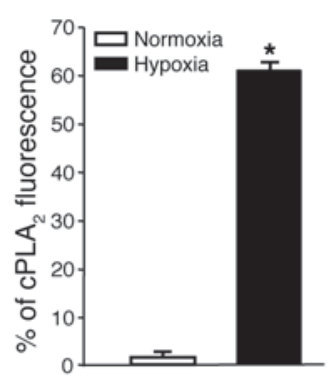
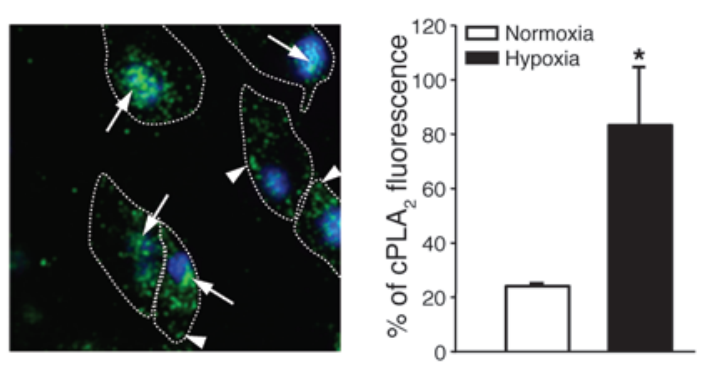

\section{Figure 8}

Translocation of endothelial $\mathrm{CPLA}_{2}$ in acute hypoxia. (A) Representative merged epifluorescence images showing endothelial cell nuclei in pulmonary arterioles, as stained by HOECHST 33324 (red), and translocated $\mathrm{CPLA}_{2}$, as detected by indirect immunofluorescence (green), in intact lungs of $\mathrm{Cx} 40^{+/+}$mice. Images were obtained at normoxia $\left(21 \% \mathrm{O}_{2}\right)$ or after 10 minutes of hypoxia $\left(1 \% \mathrm{O}_{2}\right)$; vessel margins are denoted by dotted lines. Scale bar: $50 \mu \mathrm{m}$. Group data $(n=5$ lungs each) show $\mathrm{CPLA}_{2}$ translocation as a ratio of $\mathrm{CPLA}_{2}$ immunostaining relative to HOECHST 33324 fluorescence. ${ }^{*} P<0.05$ vs. normoxia. (B) Representative merged confocal fluorescence images showing endothelial cell nuclei in cultured PAECs, as stained by HOECHST 33324 (blue), and cPLA 2 that had been translocated to the nuclear envelope (arrows) or the cell membrane (arrowheads), as detected by indirect immunofluorescence (green). Images were obtained at normoxia or after 10 minutes of hypoxia; cell margins identified by brightfield microscopy are denoted by dotted lines. Scale bar: $20 \mu \mathrm{m}$. Group data show $\mathrm{CPLA}_{2}$ translocation from $n=5$ independent experiments. ${ }^{*} P<0.05$ vs. normoxia. may be spatially distinct in the intact lung, thus raising the necessity for communication of the hypoxic signal from the area of gas exchange to the site of vasoconstriction. Ideally, this signal propagation should occur retrogradely along the pulmonary vascular tree to ensure optimal regional V/Q coupling.

In the systemic microcirculation, such retrograde signal conduction is a well-recognized mechanism known as conducted response, by which topical stimuli elicit their vasoactive effects not only locally, but also remotely in upstream resistance vessels (35). These conducted responses arise from local hyper- or depolarizations that propagate along the vascular wall through intercellular gap junction channels composed of connexins. Cx 40 presents a particularly attractive candidate to facilitate a conducted response in HPV, in that it is abundantly expressed in pulmonary tissue (13) and mediates conducted responses to electrical or pharmacological stimuli in the systemic circulation $(8,12)$. In the pulmonary circulation, expression of $\mathrm{Cx} 40$ is strictly confined to the endothelial cell layer, as confirmed by our immunofluorescence studies. In contrast to systemic blood vessels, which express $\mathrm{Cx} 40$ predominantly in arterioles (36), Cx40 was detected in endothelium of pulmonary capillaries and arterioles, which suggests this may be an ideal candidate to facilitate signal propagation from the alveolar area to upstream resistance vessels. Our finding was in line with a previous study showing that expression of a fluorescence marker protein placed under control of endogenous Cx40 transcription regulatory elements is confined to the endothelial cell layer of arterioles and capillaries in the lung, whereas veins lack expression of the protein (14).

Our results identified an essential role for Cx40 in acute HPV, given that hypoxia-induced $\triangle \mathrm{PAP}$ was largely abrogated in lungs of $C \times 40^{-/-}$mice. This finding was substantiated by calculation of $\mathrm{R}_{0}$ from pressure-flow curves, which yields a quantitatively more robust reflection of vasoconstriction, as it corrects for the nonlinearity of the pulmonary vascular pressure-flow relationship (37). Similar inhibition of HPV was achieved by the nonspecific gap junctional uncoupler $18 \alpha$-glycyrrhetinic acid, a finding in line with previous results by Morio and coworkers, who already speculated on a potential role of gap junctions in HPV (38). As Cx40 deficiency may affect the expression or cellular distribution of other connexins, including Cx37 or Cx43 (18, 39, 40), we substantiated the role of $\mathrm{Cx} 40$ using gap $27^{40}$, a mimetic peptide that prohibits connexon docking between adjacent cells due to its sequence homology with specific regions of the $\mathrm{Cx} 40$ protein (41). Neither expression nor Ser368 phosphorylation of Cx43 was reduced in $\mathrm{C} x 40^{-/-}$mice, in line with previous findings in mice with an endothelial-specific deletion in Cx40 (39), and in agreement with the notion that concomitant loss of endothelial Cx40 and $\mathrm{Cx} 43$ would cause spontaneous lung fibrosis, which is absent in $\mathrm{C} x 40^{-/-}$mice (42). Nonetheless, inhibition of $\mathrm{Cx} 43$ by gap $27^{43}$ tended to decrease HPV (albeit without reaching significance), yet this effect was additive to the inhibition of $\mathrm{Cx} 40$ by gap $27^{40}$, which indicated that the role of $\mathrm{Cx} 40$ is distinct from that of $\mathrm{Cx} 43$.

The relevance of $\mathrm{Cx} 40$ in HPV was further highlighted by arterial blood gas analyses, which suggested a higher baseline shunt and increased V/Q mismatch following partial airway occlusion in $C x 40^{-/-}$versus $C x 40^{+/+}$mice. Moreover, incremental hypoxia resulted in rapid desaturation in ${\mathrm{C} x 40^{-/-}}^{-}$mice. This vulnerability may in part be attributable to the role of $\mathrm{Cx} 40$ in electrical coupling between atrial myocytes, in that $\mathrm{Cx} 40$ deficiency may predispose mice to cardiac arrhythmias in response to hypoxia (43). Yet as indicated by spontaneous episodes of deoxygenation in $\mathrm{C} x 40^{-/-}$mice and their rapid recovery following recruitment maneuvers, $\mathrm{Cx} 40$ deficiency may simultaneously prevent redistribution of blood flow in case of spontaneous atelectases during anesthesia, and this lack of adequate V/Q matching may be particularly detrimental in hypoxia. Impaired V/Q matching was furthermore directly evidenced by fluorescent microsphere measurements during 1-lung ventilation, as blood flow distribution from the nonventilated to the ventilated lung was markedly attenuated in $\mathrm{Cx}_{40} 0^{--}$mice.

The identified role of $\mathrm{Cx} 40$, in conjunction with the notion that $\mathrm{Cx} 40$ expression is confined to capillary and arteriolar endothelial 

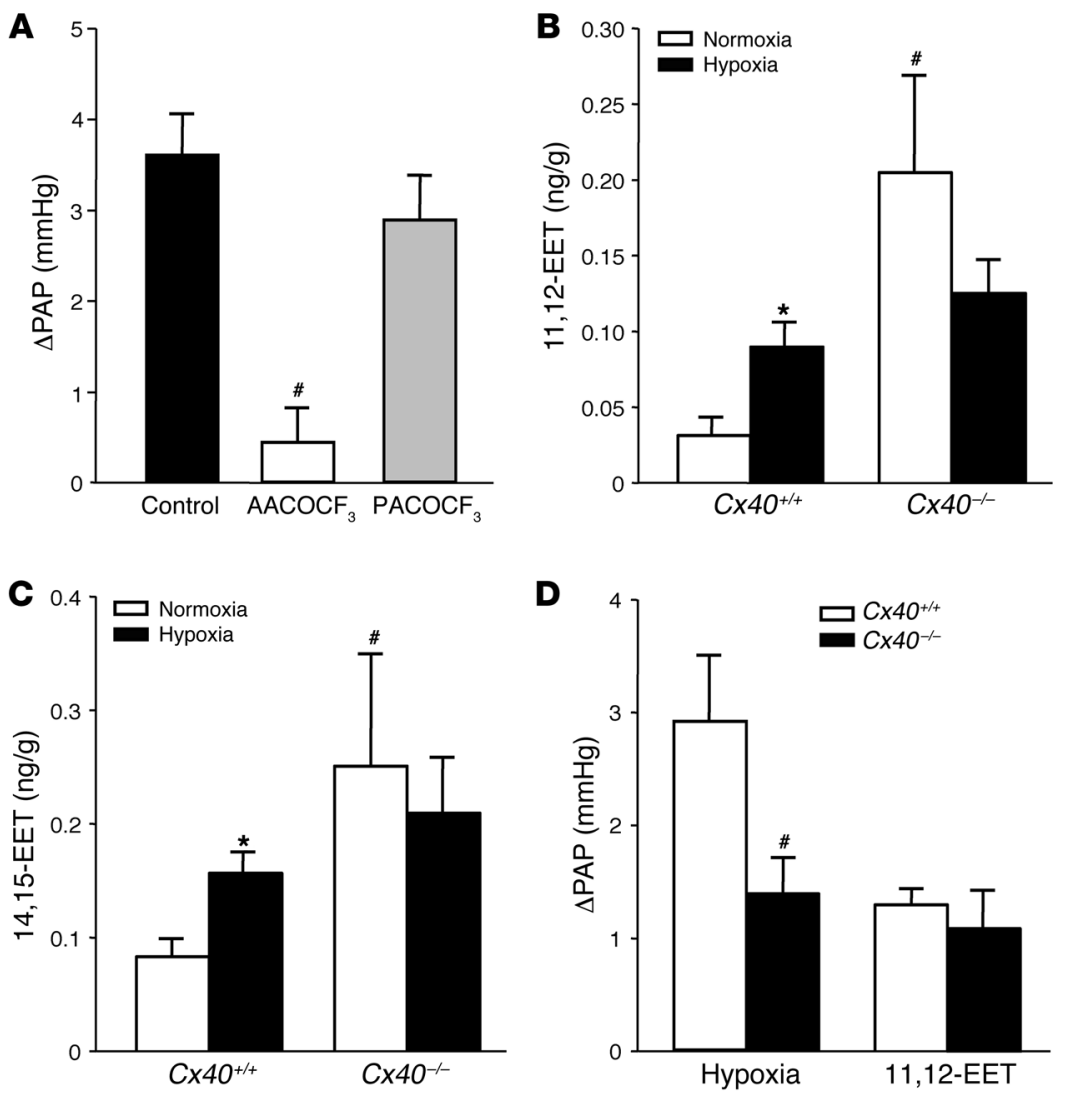

Figure 9

Role of CPLA $A_{2}$ and EETs in acute HPV. (A) Group data ( $n=5$ lungs each) showing acute HPV response, determined as $\triangle P A P 10$ minutes after hypoxia onset $\left(1 \% \mathrm{O}_{2}\right)$ versus normoxia $\left(21 \% \mathrm{O}_{2}\right)$ in untreated isolated perfused lungs of $\mathrm{Cx} 40^{+/+}$mice (control) and in lungs of $\mathrm{Cx} 40^{+/+}$mice treated with either the $\mathrm{CPLA}_{2}$-specific inhibitor $\mathrm{AACOCF}_{3}$ or the iPLA $A_{2}$-specific inhibitor PACOCF 3 (both $1 \mu \mathrm{M}$ ). ${ }^{\#} P<0.05$ vs. control. Group data showing concentrations of (B) 11,12-EET and (C) 14,15-EET in isolated lungs of $C \times 40^{+/+}$and Cx40-1- mice lungs at normoxia or after 10 minutes of hypoxia. ${ }^{*} P<0.05$ vs. normoxia; $\# P<0.05$ vs. $C \times 40^{+/+}$. (D) Group data ( $n=5$ lungs each) showing acute pulmonary vasoconstrictor response to hypoxia and exogenous infusion of 11,12-EET $(3 \mu \mathrm{M})$, determined as $\triangle \mathrm{PAP}$, in isolated lungs from $\mathrm{C} \times 40^{+/+}$and $C \times 40^{-/-}$mice. ${ }^{\#} P<0.05$ vs. $C \times 40^{+/+}$.

cells, points to a fundamental role for the lung vascular endothelium in HPV. The relevance of endothelial gap junctional communication was further confirmed by the finding that HPV was also impaired in Tie2 $\mathrm{Cre}^{+} \mathrm{C} x 40^{f l / f l} \mathrm{ApoE^{-/- }}$ mice, with endothelialspecific deletion of $\mathrm{Cx} 40$. As the relevance of the endothelium depends critically on intact lung morphology, in which areas of gas exchange and vasomotor activity are spatially separated, detailed interrogation of the mechanisms underlying the role of Cx40 in HPV must focus primarily on the intact lung preparation. To this end, real-time imaging of endothelial cells in the isolated mouse lung preparation represents an ideal approach, in that it provides direct information on the spatial and temporal profiles of intra- and interendothelial cell signaling in the intact lung vasculature (24). By fluorescence monitoring of endothelial $E_{\mathrm{m}}$ in lung microvessels, we detected that endothelial cells of both alveolar capillaries and pulmonary arterioles depolarized in response to hypoxia in intact lungs of $\mathrm{C} x 40^{+/+}$mice, with the endothelial response in capillaries preceding that in neighboring arterioles. Lack of $\mathrm{Cx} 40$ did not prevent endothelial depolarization at the capillary level, but largely blocked depolarization in upstream vessels. Taken together, these findings suggest that $\Delta E_{\mathrm{m}}$ conducts from capillaries to upstream arterioles via $\mathrm{Cx} 40$-containing gap junctions and identify the capillary endothelium as an early sensor and/or conductor of alveolar hypoxia. The subsequent propagation of the hypoxic signal via $\mathrm{Cx} 40$ is essentially in line with the established concept of a conducted response in the systemic circulation, in that local agonists evoke $\Delta E_{\mathrm{m}}$ in vascular wall cells that spreads upstream via gap junctions $(7,35)$. The finding that hypoxia caused membrane depolarization in endothelial cells of the intact lung was strongly reminiscent of the effect of hypoxia on PASMCs in vitro (44), which has been ascribed largely to the inhibition of the $\mathrm{K}_{\mathrm{V}}$ channels $K_{v} 1.5$ and $K_{v} 2.1$ (23). Results of Western blot analyses and endothelial membrane depolarization in response to 4-aminopyridine suggested that this concept may equally apply to endothelial cells, which similarly expressed functional $\mathrm{K}_{\mathrm{v}}$ channels. However, the molecular mechanisms of endothelial depolarization in hypoxia remain to be delineated in greater detail.

We recently identified a potential link between endothelial $E_{\mathrm{m}}$ and $\left[\mathrm{Ca}^{2+}\right]_{\mathrm{i}}$ in intact lungs; namely, endothelial membrane depolarization induces mibefradil-sensitive $\mathrm{Ca}^{2+}$ entry via $\alpha_{1 \mathrm{G}}$ subtype $\mathrm{T}$ type VDCCs (15). Here, we provide evidence that this mechanism is a critical constituent of the Cx40-mediated conducted response to hypoxia, in that hypoxia evoked endothelial $\Delta\left[\mathrm{Ca}^{2+}\right]_{\mathrm{i}}$ in both lung capillary and arteriolar endothelial cells that was blocked by mibefradil and was absent in Cacna1 $\mathrm{g}^{-/-}$mouse lungs. Recently, Kiefmann and colleagues reported on lung endothelial $\Delta\left[\mathrm{Ca}^{2+}\right]_{\mathrm{i}}$ in response to hypoxia triggered by reactive oxygen species production from red blood cells (45). Our present observations rule out a contribution of red blood cells to the endothelial $\left[\mathrm{Ca}^{2+}\right]_{\mathrm{i}}$ response, as lungs were imaged during blood-free perfusion. The seeming difference between our and previous data regarding the endothelial $\left[\mathrm{Ca}^{2+}\right]_{i}$ response to hypoxia in the absence of red blood cells may relate to the actual degree of hypoxia, which was more pronounced in the study by Kiefmann than in ours, as indicated by corresponding $\mathrm{PO}_{2}$ values in lung perfusate $(22 \pm 4 \mathrm{mmHg}$ vs. $40 \pm 8 \mathrm{mmHg}$ ). In $\mathrm{C} x 40^{-/-}$mice, hypoxia-induced endothelial $\Delta\left[\mathrm{Ca}^{2+}\right]_{i}$ was largely blocked in arterioles, yet not in capillaries, which suggests that the arteriolar response is the result of $\mathrm{Cx} 40$ mediated signal propagation. This notion is in line with our finding that arteriolar but not capillary endothelial depolarization in response to hypoxia was attenuated in $C \times 40^{-/-}$mice. The finding that endothelial depolarization was not attenuated in Cacna1 $\mathrm{g}^{-1-}$ mice or by treatment with the intracellular $\mathrm{Ca}^{2+}$ chelator BAPTA$\mathrm{AM}$, and by itself sufficed to stimulate $\alpha_{1 \mathrm{G}}$-mediated $\mathrm{Ca}^{2+}$ entry (15), further suggests that the actual propagated signal is primarily a charge transfer (i.e., $\Delta E_{\mathrm{m}}$ ) causing a secondary $\mathrm{Ca}^{2+}$ influx via $\alpha_{1 \mathrm{G}}$ subtype $T$ type channels, rather than an intercellular transfer of $\mathrm{Ca}^{2+}$ itself. The functional relevance of the hypoxia-induced, $\mathrm{Cx} 40$-propagated, and $\alpha_{1 \mathrm{G}}$-mediated endothelial $\left[\mathrm{Ca}^{2+}\right]_{\mathrm{i}}$ response is 


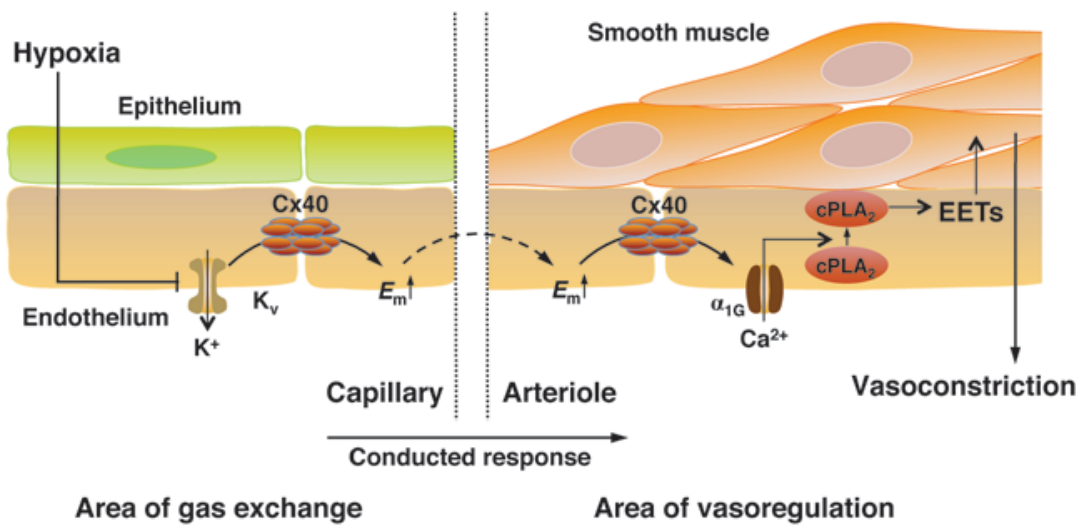

Figure 10

Proposed concept for a conducted response propagated via endothelial Cx40 in HPV The scheme encompasses (i) proposed signaling events at the level of the alveolar site of gas exchange (left), in which hypoxia induces endothelial membrane depolarization $\left(E_{\mathrm{m}} \uparrow\right)$ in lung capillaries, potentially by inhibition of oxygen-sensitive $\mathrm{K}_{\mathrm{v}}$ channels; (ii) retrograde propagation of endothelial membrane depolarization from alveolar capillaries to upstream arterioles via Cx40 (middle), and (iii) elicitation of a vasoconstrictive response at the level of the upstream arteriole (right) through activation of the $\alpha_{1 G}$ subtype T type VDCC, subsequent activation of $\mathrm{CPLA}$, and formation of EETs, which may serve as either direct (intercellular) or indirect (intracellular) mediators of smooth muscle cell contraction.

highlighted by our finding that HPV was blocked by endothelialspecific $\mathrm{Ca}^{2+}$ chelation.

The generation of prostanoids and other AA metabolites constitutes a key mechanism by which endothelial $\mathrm{Ca}^{2+}$ signals evoke vasoactive responses. In lung endothelial cells, the release of AA from membrane phospholipids is primarily mediated by $\mathrm{CLA}_{2}$ (25), which requires $\mathrm{Ca}^{2+}$-dependent translocation from the cytosol to the cell membrane and the nuclear envelope (27). We showed that hypoxia stimulated the translocation of $\mathrm{CPLA}_{2}$ in pulmonary endothelial cells and that $\mathrm{CPLA}_{2}$ activity was essential for an intact HPV response, a finding in line with the previous demonstration of an attenuated HPV response in $\mathrm{CPLA}_{2 \alpha}$-deficient mice (46).

EETs, which are generated from AAs by the cytochrome P450 (CYP) enzymes CYP2C and CYP2J in the cardiovascular system, present a particularly attractive candidate for endothelial-derived AA metabolites that may trigger PASMC contraction in the context of HPV. First, 11,12-EET - but potentially also the regioisomers 5,6-EET, 8,9-EET, and 14,15-EET - is a potent endothelial-derived vasoconstrictor in the pulmonary circulation $(26,47)$. In parallel to the divergent effects of hypoxia in systemic and pulmonary blood vessels, EETs induce vasorelaxation in resistance vessels of the systemic circulation (48). Second, CYPs are abundantly expressed in the lung (49), and CYP2J in particular is strongly expressed in human pulmonary endothelium (50). Third, levels of 11,12-EET and 14,15-EET increase in microsomes of isolated mouse lungs during hypoxia and also contribute to HPV; namely, CYP inhibition by fenbendazole attenuates HPV, whereas inhibition of EET degradation by soluble epoxyhydrolase enhances it $(26,51)$. Here, we showed that hypoxia increased levels of 11,12-EET and 14,15-EET in isolated perfused lungs of $\mathrm{C} x 40^{+/+}$mice, but not in $\mathrm{C} x 40^{-/-}$lungs. This finding is in line with the view that EETs may be critical to trigger arteriolar vasoconstriction downstream of the Cx40-propagated conducted response, a notion that is further supported by our finding that stimulation with exogenous 11,12-EET elicited a similar pulmonary vasopressor response in $\mathrm{C} x 40^{+/+}$and $\mathrm{C} x 40^{-/-}$mice.
Although exogenous EETs can trigger TRPC6 translocation and thus facilitate $\mathrm{Ca}^{2+}$ entry and contraction in PASMCs (26), our finding that fairly high concentrations of 11,12-EET were required to cause a relatively modest $\triangle \mathrm{PAP}$ suggests that EETs may not act as direct intercellular mediators, but rather indirectly as intracellular signaling molecules that regulate signal conduction from the endothelium to smooth muscle cells. This view is in line with data from the systemic circulation, in which EETs were initially believed to directly mediate vasodilation, but were subsequently shown to act primarily by promoting endothelial hyperpolarization, myoendothelial gap junctional communication, and/ or increasing extracellular $\left[\mathrm{K}^{+}\right]$(52). Remarkably, EETs may also dynamically modulate interendothelial gap junctional communication (53). The reported biphasic effect of EETs, with a transient increase in interendothelial electrical coupling followed by sustained uncoupling (53), may thus account in part for the well-described temporal profile of the HPV response, with an initial maximum and a subsequent nadir (28). Notably, basal EET levels were markedly upregulated in lungs of $\mathrm{C} \times 40^{-/-}$compared with $\mathrm{C} x 40^{+/+}$mice. As these higher EET levels were not associated with a corresponding increase in basal pulmonary vascular tone, despite unabated pulmonary reactivity to EETs, EET production in $\mathrm{C} x 40^{-/-}$lungs may be compartmentalized and - just like hypoxia-induced endothelial $E_{\mathrm{m}}$ and $\left[\mathrm{Ca}^{2+}\right]_{\mathrm{i}}$ signaling - confined to lung capillaries, a notion that cannot currently be tested given the lack of sensitive single-cell EETs assays.

The involvement of a Cx40-mediated conducted response in HPV may provide a mechanistic explanation for the characteristic failure of HPV in the clinical settings of systemic inflammatory disorders $(54,55)$ or during administration of volatile anesthetics $(56,57)$. Indeed, inflammatory stimuli rapidly impair interendothelial coupling via $\mathrm{Cx} 40$ (58) and decrease its expression in lungs (13), while volatile anesthetics have long been known to inhibit gap junctional communication $(59,60)$. Furthermore, our finding that $\mathrm{Cx} 40$ was not only required for an intact HPV, but of equal relevance in chronic hypoxic pulmonary hypertension and vascular remodeling, identified a critical role for gap junctional communication in chronic hypoxic lung disease.

In conclusion, the results of the present study delineate a mechanistic concept for HPV: alveolar hypoxia is sensed at the alveolocapillary level, from which the response is retrogradely conducted along the endothelial cell layer via $\mathrm{Cx} 40$-containing gap junctions to upstream arterioles, where it causes vasoconstriction. This paradigm of HPV ascribes a pivotal role to the vascular endothelium as an essential signal conductor in the intact lung and identifies $\mathrm{Cx} 40$ as a potential target for therapeutic modulation of HPV in conditions of either impaired or exaggerated HPV responses as well as in chronic hypoxic lung disease.

\section{Methods}

Further information can be found in Supplemental Methods, available online with this article; doi:10.1172/JCI59176DS1.

Animals. Experiments were performed in male mice deficient in Cx40 (Cx40-/- mice; ref. 43) or the $\alpha_{1 \mathrm{G}}$ subtype $\mathrm{T}$ type $\mathrm{Ca}^{2+}$ channel (Cacna1g 
mice) or in mice with endothelial-specific deletion of $\mathrm{Cx} 40$ on an $A p o E^{-/-}$ background (Tie2 $\mathrm{Cre}^{+} \mathrm{C} \times 40^{f / f l} \mathrm{ApoE^{-/- }}$ mice; ref. 39) of 20-30 g body weight, and their respective wild-type littermates $\left(\mathrm{C} x 40^{+/+}\right.$and $\left.\mathrm{Cacna1} \mathrm{g}^{+/+}\right)$and crelox controls (Tie2 $\mathrm{Cre}^{+} \mathrm{ApoE} \mathrm{E}^{-/-}$and $\mathrm{C} x 40^{\mathrm{fl} / \mathrm{f}} \mathrm{ApoE^{-/- }}$ ).

Isolated perfused mouse lung. Isolated lungs were prepared and perfused with HBSS containing $5 \%$ bovine serum albumin and $5 \%$ dextran. $\triangle \mathrm{PAP}$ was recorded in response to a change from normoxic $\left(21 \% \mathrm{O}_{2}\right.$; yielding $137.5 \pm 4.6 \mathrm{mmHg} \mathrm{PO}_{2}$ in the lung effluate) to hypoxic $\left(1 \% \mathrm{O}_{2}\right.$; yielding

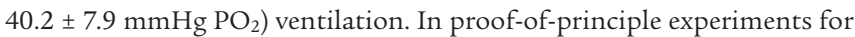
the involvement of $\mathrm{Cx} 40$ in $\mathrm{HPV}$, we additionally calculated $\mathrm{R}_{0}$ (i.e., the resistance that would exist if the lung vessels were at their respective diameter at 0 vascular pressure) from nonlinear regression analyses of pressureflow curves (54). Connexin-specific mimetic peptides for inhibition of gap junctional communication were administered 30 minutes prior to hypoxia.

Oxygenation during regional and global hypoxia in vivo. In anesthetized and mechanically ventilated mice, ventilation inhomogeneities were induced by tracheal instillation of $25 \mu \mathrm{l}$ saline, causing occlusion of a fraction of the larger airways (28). Blood gas analyses were performed before and 2 and 10 minutes after saline instillation. For global hypoxia, $\mathrm{SaO}_{2}$ was monitored continuously, and $\mathrm{FIO}_{2}$ was gradually decreased from 0.21 . In case of a sudden $\mathrm{SaO}_{2}$ decrement, a recruitment maneuver was performed to counteract potential atelectases.

$V / Q$ matching in vivo. Anesthetized mice were subjected to 1-lung ventilation via a tracheal tube wedged into the left main bronchus. Yellow-green fluorescent microspheres $\left(1.5 \times 10^{5}\right.$ beads; $15 \mu \mathrm{m}$ diameter $)$ were injected intravenously, and lungs and right kidney were harvested and digested (61). Microspheres were collected on $10-\mu \mathrm{m}$ filters, and fluorescence was solved and quantified by fluorometry. Fluorescence was related to lung weight and expressed as percent total lung blood flow for both the ventilated and the nonventilated lung.

Chronic hypoxia experiments. $\mathrm{C} x 40^{+/+}$and $\mathrm{C} x 40^{-/-}$mice were housed at either normoxia $\left(21 \% \mathrm{O}_{2}\right)$ or hypoxia $\left(10 \% \mathrm{O}_{2}\right)$ for 5 weeks, at which time right ventricular systolic pressure was determined by a $1.4 \mathrm{~F}$ microtip Millar catheter. Right ventricular hypertrophy was calculated as the Fulton index (i.e., right ventricular weight divided by the sum of septal and left ventricular weights), and the percentage of non-, partially, and fully muscularized lung microvessels was assessed from H\&E-stained lung sections as described previously (62).

Real-time fluorescence imaging. Real-time fluorescence imaging was performed in isolated perfused mouse lungs as previously reported $(24,63)$. For measurement of $E_{\mathrm{m}}$ and cytosolic $\left[\mathrm{Ca}^{2+}\right]_{\mathrm{i}}$, endothelial cells were loaded in situ by di-8-ANEPPS and fura-2, respectively. Endothelial fluorescence in lung arterioles and capillaries was excited and imaged at the appropriate wavelengths. $\Delta E_{\mathrm{m}}$ was calculated based on the calibration of di-8-ANEPPS fluorescence by lung perfusion with different $\left[\mathrm{K}^{+}\right](64)$. Endothelial $\left[\mathrm{Ca}^{2+}\right]_{\mathrm{i}}$ was determined from the $340 / 380$ fura- 2 ratio based on $K_{\mathrm{d}}$ of $224 \mathrm{nM}$ and appropriate calibration parameters (65).

cPLA $A_{2}$ translocation. Translocation of $\mathrm{PLA}_{2}$ from the cytosolic to the membrane-bound fraction was imaged in endothelial cells of the isolated perfused lung and in cultured PAECs by indirect immunofluorescence, as previously described $(27,66)$. This assay stains specifically for translocated (i.e. membrane-bound) as opposed to nonactivated, cytoplasmic CPLA 2 . In brief, lungs were ventilated with normoxic or hypoxic gas mixture for 10 minutes. Endothelial cell membranes were then permeabilized in situ by $0.5 \%$ Triton $\mathrm{X}-100$, allowing for subsequent cell loading with primary anti-cPLA 2 and corresponding FITC-conjugated secondary antibodies, while concomitantly causing loss of unbound cytoplasmic molecules such as nonactivated $\mathrm{CPLA}_{2}$ when cells were subsequently washed. As a result, immunofluorescent staining for $\mathrm{CPLA}_{2}$ is absent in unstimulated cells, where cytoplasmic $\mathrm{CPLA}_{2}$ has been washed out, whereas $\mathrm{CPLA}_{2}$ fluorescence is evident in activated endothelial cells, in which $\mathrm{CPLA}_{2}$ has translocated to the cell membrane or the nuclear envelope. Endothelial nuclei were counterstained by HOECHST 33342 .

Fluorescence immunohistology and Western blot analyses. Cryoslices of $\mathrm{C} x 40^{+/+}$ and $\mathrm{C} x 40^{-/-}$mice were incubated with primary antibodies against vWF, $\mathrm{Cx} 40$, or $\mathrm{Cx} 43$ and stained by appropriate secondary fluorescence antibodies. Expression of $\mathrm{Cx} 43$ and phospho-Cx 43 was detected by Western blot analyses from whole lung homogenate. For $\mathrm{K}_{\mathrm{v}}$ channels, Western blot analyses from whole lung homogenate and fresh lung endothelial cells were performed.

Detection of EETs. Isolated mouse lungs were perfused at normoxia or hypoxia for 10 minutes, snap frozen, and homogenized in liquid nitrogen. Samples were extracted, and EETs were determined with a Sciex API4000 mass spectrometer as described previously (67).

Statistics. Data are presented as mean \pm SEM. Statistical analyses were performed using SigmaStat software (SigmaStat 3.1; JandelScientific). Statistical significance was determined by 2 -tailed Student's $t$ test or 1-way ANOVA as appropriate. A $P$ value less than 0.05 was considered significant.

Study approval. The study was approved by the Institutional Animal Care and Use Committee of St. Michael's Hospital. All experiments were performed in accordance with the Guide for the Care and Use of Laboratory Animals (Institute of Laboratory Animal Resources, 7th edition 1996).

\section{Acknowledgments}

The authors thank Judy Trogadis (The Keenan Research Centre) for excellent assistance with confocal microscopy, Beate Fuchs for providing rat PASMCs, and Andreas Zakrzewicz for providing HUVECs. This study was supported by the Canadian Institutes of Health Research (CIHR MOP no. 93584), the Heart \& Stroke Foundation Ontario (NA no. 6900), the McLaughlin Foundation, and the Kaiserin-Friedrich Foundation Berlin.

Received for publication May 25, 2011, and accepted in revised form August 30, 2012.

Address correspondence to: Wolfgang M. Kuebler, The Keenan Research Centre, Li Ka Shing Knowledge Institute, St. Michael's Hospital, 209 Victoria Street, M5B 1W8 Toronto, Ontario, Canada. Phone: 416.864.5924; Fax: 416.864.5958; E-mail: kueblerw@smh.ca.
1. Ward JP, McMurtry IF. Mechanisms of hypoxic pulmonary vasoconstriction and their roles in pulmonary hypertension: new findings for an old problem. Curr Opin Pharmacol. 2009;9(3):287-296.

2. Maggiorini M, et al. High-altitude pulmonary edema is initially caused by an increase in capillary pressure. Circulation. 2001;103(16):2078-2083.

3. Dawson CA. Role of pulmonary vasomotion in physiology of the lung. Physiol Rev. 1984;64(2):544-616.

4. Paddenberg R, Konig P, Faulhammer P, Goldenberg A, Pfeil U, Kummer W. Hypoxic vasoconstriction of partial muscular intra-acinar pulmonary arteries in murine precision cut lung slices. Respir
Res. 2006;7:93.

5. Hislop A, Reid L. Normal structure and dimensions of the pulmonary arteries in the rat. J Anat. 1978; 125(pt 1):71-83.

6. Tabuchi A, Mertens M, Kuppe H, Pries AR, Kuebler WM. Intravital microscopy of the murine pulmonary microcirculation. J Appl Physiol. 2008; 104(2):338-346.

7. Figueroa XF, Duling BR. Gap junctions in the control of vascular function. Antioxid Redox Signal. 2009; 11(2):251-266.

8. de Wit C, et al. Impaired conduction of vasodilation along arterioles in connexin40-deficient mice.
Circ Res. 2000;86(6):649-655.

9. Severs NJ, et al. Immunocytochemical analysis of connexin expression in the healthy and diseased cardiovascular system. Microsc Res Tech. 2001;52(3):301-322.

10. Gabriels JE, Paul DL. Connexin 43 is highly localized to sites of disturbed flow in rat aortic endothelium but connexin 37 and connexin 40 are more uniformly distributed. Circ Res. 1998;83(6):636-643.

11. Simon AM, McWhorter AR, Chen H, Jackson CL, Ouellette Y. Decreased intercellular communication and connexin expression in mouse aortic endothelium during lipopolysaccharide-induced inflammation. J Vasc Res. 2004;41(4):323-333. 
12. Wolfle SE, et al. Connexin 45 cannot replace the function of connexin 40 in conducting endotheliumdependent dilations along arterioles. Circ Res. 2007; 101(12):1292-1299.

13. Rignault S, Haefliger JA, Waeber B, Liaudet L, Feihl F. Acute inflammation decreases the expression of connexin 40 in mouse lung. Shock. 2007;28(1):78-85.

14. Tallini YN, et al. Propagated endothelial Ca2+ waves and arteriolar dilation in vivo: measurements in Cx40BAC-GCaMP2 transgenic mice. Circ Res. 2007;101(12):1300-1309.

15. Zhou C, et al. $\alpha_{1 \mathrm{G}} \mathrm{T}$-type calcium channel selectively regulates $\mathrm{P}$-selectin surface expression in pulmonary capillary endothelium. Am J Pbysiol Lung Cell Mol Physiol. 2010;299(1):L86-L97.

16. Parthasarathi $\mathrm{K}$, et al. Connexin 43 mediates spread of $\mathrm{Ca}^{2+}$-dependent proinflammatory responses in lung capillaries. JClin Invest. 2006;116(8):2193-2200.

17. Bao X, Reuss L, Altenberg GA. Regulation of purified and reconstituted connexin 43 hemichannels by protein kinase C-mediated phosphorylation of Serine 368. J Biol Chem. 2004;279(19):20058-20066.

18. Isakson BE, Damon DN, Day KH, Liao Y, Duling BR Connexin 40 and connexin 43 in mouse aortic endothelium: evidence for coordinated regulation. Am J Physiol Heart Circ Physiol. 2006;290(3):H1199-H1205.

19. de Wit C. Connexins pave the way for vascular communication. News Physiol Sci. 2004;19:148-153.

20. Platoshyn O, Yu Y, Ko EA, Remillard CV, Yuan JX. Heterogeneity of hypoxia-mediated decrease in $\mathrm{I}_{\mathrm{K}(\mathrm{V})}$ and increase in $[\mathrm{Ca} 2+]$ cyt in pulmonary artery smooth muscle cells. Am J Physiol Lung Cell Mol Physiol. 2007;293(2):L402-L416.

21. Archer SL, et al. Molecular identification of the role of voltage-gated $\mathrm{K}^{+}$channels, Kv1.5 and Kv2.1, in hypoxic pulmonary vasoconstriction and control of resting membrane potential in rat pulmonary artery myocytes. J Clin Invest. 1998;101(11):2319-2330.

22. Moudgil R, Michelakis ED, Archer SL. The role of $\mathrm{K}^{+}$channels in determining pulmonary vascular tone, oxygen sensing, cell proliferation, and apoptosis: implications in hypoxic pulmonary vasoconstriction and pulmonary arterial hypertension. Microcirculation. 2006;13(8):615-632.

23. Archer SL, et al. Preferential expression and function of voltage-gated, $\mathrm{O}_{2}$-sensitive $\mathrm{K}^{+}$channels in resistance pulmonary arteries explains regional heterogeneity in hypoxic pulmonary vasoconstriction: ionic diversity in smooth muscle cells. Circ Res. 2004 95(3):308-318

24. Kuebler WM, Parthasarathi K, Lindert J, Bhattacharya J. Real-time lung microscopy. J Appl Physiol. 2007;102(3):1255-1264.

25. Chakraborti S, Michael JR, Chakraborti T. Role of an aprotinin-sensitive protease in protein kinase $\mathrm{C} \alpha$-mediated activation of cytosolic phospholipase $\mathrm{A}_{2}$ by calcium ionophore (A23187) in pulmonary endothelium. Cell Signal. 2004;16(6):751-762.

26. Keserü B, et al. Epoxyeicosatrienoic acids and the soluble epoxide hydrolase are determinants of pulmonary artery pressure and the acute hypoxic pulmonary vasoconstrictor response. FASEB J. 2008;22(12):4306-4315.

27. Schievella AR, Regier MK, Smith WL, Lin LL. Calcium-mediated translocation of cytosolic phospholipase $\mathrm{A}_{2}$ to the nuclear envelope and endoplasmic reticulum. J Biol Chem. 1995;270(51):30749-30754.

28. Weissmann $\mathrm{N}$, et al. Classical transient receptor potential channel 6 (TRPC6) is essential for hypoxic pulmonary vasoconstriction and alveolar gas exchange. Proc Natl Acad Sci USA. 2006; 103(50):19093-19098.
29. Sommer N, et al. Regulation of hypoxic pulmonary vasoconstriction: basic mechanisms. Eur Respir J. 2008;32(6):1639-1651.

30. Madden JA, Vadula MS, Kurup VP. Effects of hypoxia and other vasoactive agents on pulmonary and cerebral artery smooth muscle cells. Am J Physiol. 1992; 263(3 pt 1):L384-L393.

31. Ogata M, Ohe M, Katayose D, Takishima T. Modulatory role of EDRF in hypoxic contraction of isolated porcine pulmonary arteries. Am J Physiol. 1992; 262(3 pt 2):H691-H697.

32. Jabr RI, Toland H, Gelband CH, Wang XX, Hume $J R$. Prominent role of intracellular $\mathrm{Ca}^{2+}$ release in hypoxic vasoconstriction of canine pulmonary artery. Br J Pharmacol. 1997;122(1):21- 30.

33. Young I, Mazzone RW, Wagner PD. Identification of functional lung unit in the dog by graded vascular embolization. J Appl Physiol. 1980;49(1):132-141.

34. Guntheroth WG, Luchtel DL, Kawabori I. Pulmonary microcirculation: tubules rather than sheet and post. J Appl Physiol. 1982;53(2):510-515.

35. de Wit C, Griffith TM. Connexins and gap junctions in the EDHF phenomenon and conducted vasomotor responses. Pflugers Arch. 2010;459(6):897-914.

36. Looft-Wilson RC, Payne GW, Segal SS. Connexin expression and conducted vasodilation along arteriolar endothelium in mouse skeletal muscle. J Appl Physiol. 2004;97(3):1152-1158.

37. Linehan JH, Haworth ST, Nelin LD, Krenz GS, Dawson CA. A simple distensible vessel model for interpreting pulmonary vascular pressure-flow curves. J Appl Physiol. 1992;73(3):987- 994.

38. Morio Y, Carter EP, Oka M, McMurtry IF. EDHFmediated vasodilation involves different mechanisms in normotensive and hypertensive rat lungs. $A m \mathrm{~J}$ Physiol Heart Circ Physiol. 2003;284(5):H1762-H1770.

39. Chadjichristos CE, et al. Endothelial-specific deletion of connexin 40 promotes atherosclerosis by increasing CD73-dependent leukocyte adhesion. Circulation. 2010;121(1):123-131.

40. Alonso F, Boittin FX, Beny JL, Haefliger JA. Loss of connexin 40 is associated with decreased endothelium-dependent relaxations and eNOS levels in the mouse aorta. Am J Physiol Heart Circ Physiol. 2010;299(5):H1365-H1373.

41. Chaytor AT, Martin PE, Evans WH, Randall MD, Griffith TM. The endothelial component of cannabinoid-induced relaxation in rabbit mesenteric artery depends on gap junctional communication. J Physiol. 1999;520:539-550.

42. Koval M, et al. Spontaneous lung dysfunction and fibrosis in mice lacking connexin 40 and endothelial cell connexin 43. Am J Pathol. 2011;178(6):2536-2546.

43. Kirchhoff S, Nelles E, Hagendorff A, Kruger O, Traub $\mathrm{O}$, Willecke K. Reduced cardiac conduction velocity and predisposition to arrhythmias in connexin40deficient mice. Curr Biol. 1998;8(5):299-302.

44. Moudgil R, Michelakis ED, Archer SL. Hypoxic pulmonary vasoconstriction. J Appl Physiol. 2005; 98(1):390-403.

45. Kiefmann R, Rifkind JM, Nagababu E, Bhattacharya J. Red blood cells induce hypoxic lung inflammation. Blood. 2008;111(10):5205-5214.

46. Ichinose $\mathrm{F}$, et al. Cytosolic phospholipase $\mathrm{A}_{2}$ in hypoxic pulmonary vasoconstriction. J Clin Invest. 2002;109(11):1493-1500.

47. Zhu D, et al. Epoxyeicosatrienoic acids constrict isolated pressurized rabbit pulmonary arteries. AmJ Physiol Lung Cell Mol Physiol. 2000;278(2):L335-L343.

48. Fleming I, Busse R. Endothelium-derived epoxyeicosatrienoic acids and vascular function. Hypertension. 2006;47(4):629-633.
49. Hukkanen J, Pelkonen O, Hakkola J, Raunio H. Expression and regulation of xenobiotic-metabolizing cytochrome P450 (CYP) enzymes in human lung. Crit Rev Toxicol. 2002;32(5):391-411.

50. Zeldin DC, et al. CYP2J subfamily P450s in the lung: expression, localization, and potential functional significance. Mol Pharmacol. 1996;50(5):1111-1117.

51. Pokreisz P, et al. Cytochrome P450 epoxygenase gene function in hypoxic pulmonary vasoconstriction and pulmonary vascular remodeling. Hypertension. 2006;47(4):762-770.

52. Busse R, Edwards G, Feletou M, Fleming I, Vanhoutte PM, Weston AH. EDHF: bringing the concepts together. Trends Pharmacol Sci. 2002;23(8):374-380.

53. Popp R, Brandes RP, Ott G, Busse R, Fleming I. Dynamic modulation of interendothelial gap junctional communication by 11,12-epoxyeicosatrienoic acid. Circ Res. 2002;90(7):800-806.

54. Spöhr F, et al. 4-Aminopyridine restores impaired hypoxic pulmonary vasoconstriction in endotoxemic mice. Anesthesiology. 2007;107(4):597-604

55. Petersen B, et al. Activation of Toll-like receptor 2 impairs hypoxic pulmonary vasoconstriction in mice. Am J Physiol Lung Cell Mol Physiol. 2008; 294(2):L300-L308.

56. Groh J, Kuhnle GE, Sckell A, Ney L, Goetz AE. Isoflurane inhibits hypoxic pulmonary vasoconstriction. An in vivo fluorescence microscopic study in rabbits. Anesthesiology. 1994;81(6):1436-1444.

57. Ishibe Y, Gui X, Uno H, Shiokawa Y, Umeda T, Suekane K. Effect of sevoflurane on hypoxic pulmonary vasoconstriction in the perfused rabbit lung. Anesthesiology. 1993;79(6):1348-1353.

58. Bolon ML, Kidder GM, Simon AM, Tyml K. Lipopolysaccharide reduces electrical coupling in microvascular endothelial cells by targeting connexin 40 in a tyrosine-, ERK1/2-, PKA-, and PKC-dependent manner. J Cell Physiol. 2007;211(1):159-166.

59. Masaki E, Kawamura M, Kato F. Attenuation of gap-junction-mediated signaling facilitated anesthetic effect of sevoflurane in the central nervous system of rats. Anesth Analg. 2004;98(3):647-652.

60. He DS, Burt JM. Mechanism and selectivity of the effects of halothane on gap junction channel function. Circ Res. 2000;86(11):E104-E109.

61. Glenny RW, Bernard S, Brinkley M. Validation of fluorescent-labeled microspheres for measurement of regional organ perfusion. J Appl Physiol. 1993;74(5):2585-2597.

62. Hoffmann J, et al. Mast cells promote lung vascular remodelling in pulmonary hypertension. Eur RespirJ. 2011;37(6):1400-1410

63. Yin J, et al. Negative-feedback loop attenuates hydrostatic lung edema via a cGMP-dependent regulation of transient receptor potential vanilloid 4 . Circ Res. 2008;102(8):966-974.

64. Song C, Al-Mehdi AB, Fisher AB. An immediate endothelial cell signaling response to lung ischemia. Am J Physiol Lung Cell Mol Physiol. 2001; 281(4):L993-L1000

65. Kuebler WM, Ying X, Singh B, Issekutz AC, Bhattacharya J. Pressure is proinflammatory in lung venular capillaries. J Clin Invest. 1999;104(4):495-502.

66. Kuebler WM, Parthasarathi K, Wang PM, Bhattacharya J. A novel signaling mechanism between gas and blood compartments of the lung. J Clin Invest. 2000;105(7):905-913.

67. Michaelis UR, Fisslthaler B, Barbosa-Sicard E, Falck JR, Fleming I, Busse R. Cytochrome P450 epoxygenases $2 \mathrm{C} 8$ and $2 \mathrm{C} 9$ are implicated in hypoxia-induced endothelial cell migration and angiogenesis. J Cell Sci. 2005;118(pt 23):5489-5498. 